\title{
La traducción en la prensa temprana: la Gaceta de Guatemala (1797-1807) y sus fuentes foráneas ${ }^{1}$
}

\author{
Aura E. Navarro \\ auranavarro@gmail.com \\ Grupo de investigación HISTAL, Canadá
}

\section{Resumen}

A pesar de no haber conseguido todavía el reconocimiento crítico que merece, la Gaceta de Guatemala, en su tercera serie (1797-1807), se puede considerar uno de los periódicos más importantes de la Hispanoamérica colonial. Experimentó, en particular, una actividad traductiva significativa, gracias a la presencia de un grupo de individuos excepcionales, procedentes de horizontes sociales, geográficos y académicos diversos, pero hermanados por una inquietud intelectual común y por una preocupación por la mejora social y económica no solo del Reino (que iba desde Chiapas a Costa Rica), sino también de la nación española. A pesar de la importante censura por parte de las autoridades, los editores de la Gaceta y sus colaboradores tuvieron acceso directa e indirectamente a una cantidad considerable de obras extranjeras y lograron incorporar un gran número de traducciones en diferentes modalidades (traducciones literales, resúmenes, paráfrasis de fragmentos o textos más amplios). El rastreo minucioso de esta tercera serie ha permitido identificar y caracterizar una actividad traductiva tan rica como variada, dando luces sobre el dinamismo intelectual de esta región centroamericana.

Palabras clave: América Central; Gaceta de Guatemala; Hispanoamérica colonial; periodismo; traducción.

\section{Translation in Early Press: Gaceta de Guatemala (1797-1807) and its Foreign Sources}

\begin{abstract}
Although not yet fully recognized as such, the third series of the Gaceta de Guatemala (1797-1807) may be considered as one of the leading newspapers of the colonial period in Spanish America. It reflected a significant translation activity, thanks to the presence of a group of exceptional individuals from diverse social, geographical and academic backgrounds. Despite this diversity they were connected
\end{abstract}

1 Este artículo forma parte de un proyecto de investigación en curso sobre prensa hispánica temprana (Université de Montréal). 
by common intellectual interests and a concern for the social and economic improvement not only of the Kingdom (from Chiapas to Costa Rica) but also of the Spanish Nation. Notwithstanding the significant censorship by the Spanish authorities, the editors of the Gaceta and their close collaborators had direct or indirect access to a considerable number of foreign works and they managed to incorporate numerous translations in different modalities (literal translations, summaries and paraphrases of fragments or more substantial writings). A thorough follow-up on this third series has allowed us to identify and characterize a translation activity as rich as it is varied, shedding light on the intellectual dynamism of this Central American region.

Keywords: periodical press; Central America; translation; Colonial Spanish America.

\section{La traduction dans la presse ancienne: la Gaceta de Guatemala (1797-1807) et ses sources étrangères}

\section{Résumé}

Bien qu'elle n'ait pas encore obtenu la reconnaissance critique qui lui est due, la troisième série de la Gaceta de Guatemala (1797-1807) peut être considérée comme l'un des grands journaux de la période coloniale en Amérique hispanique. Elle a manifesté, en particulier, une importante activité de traduction, grâce à la présence d'un groupe d'individus exceptionnels provenant des milieux sociaux, géographiques et académiques divers, mais unis par des intérêts intellectuels et des préoccupations communes visant l'amélioration sociale et économique non seulement du Royaume (du Chiapas au Costa Rica), mais également de la Nation espagnole. Malgré une censure importante de la part des autorités, les éditeurs de la Gaceta et leurs collaborateurs eurent accès, directement et indirectement, à une quantité considérable d'œuvres étrangères. Ils réussirent à intégrer un grand nombre de traductions sous différentes modalités (traductions littérales, résumés, paraphrases de fragments ou de textes plus longs). L'examen minutieux de cette troisième série nous a permis d'identifier et de caractériser une activité de traduction aussi riche que variée, mettant ainsi en lumière le dynamisme intellectuel de cette région d'Amérique centrale.

Mots clés : journalisme ; Amérique centrale ; traduction journalistique ; Amérique hispanique coloniale. 


\section{Introducción}

"En los mares de las quatro partes del mundo se han señoreado los Ingleses, causando una total interrupción de comercio à nuestra España con sus colonias", lamentaba en 1800 , desde la capital de Guatemala, el negociante Juan Bautista Irisarri. ${ }^{2}$ Esta situación, que provocó el colapso de la economía de la región, se había iniciado cuatro años antes y duró hasta 1808, prácticamente sin interrupciones. ${ }^{3}$ En estas circunstancias, se podía esperar poco de una provincia periférica de la Monarquía española, con frecuencia caracterizada como adormecida y mediocre. ${ }^{4}$

Paradójicamente, sin embargo, en esos mismos años, el llamado "Reino de Guatemala", 5 al que correspondía un amplio perímetro administrativo que iba desde Chiapas a Costa Rica, conoció un florecimiento intelectual y una proyección más allá de sus fronteras, en una forma que no se había experimentado hasta la fecha ${ }^{6}$ En ese período, breve pero intenso, la prensa periódica actuó como cauce y motor principal de los modos cultos de expresión, y de las

2 "Carta de Chirimía sobre el estado mercantil presente de este Reyno", Gaceta de Guatemala (en adelante GG) (III, 1800, núm. 141, p. 153). Para todas las citas textuales de la época, se mantiene la ortografía de los originales.

3 Son los trece meses de la Paz de Amiens, aunque el cese de las hostilidades había empezado ya en 1801, con los preliminares de la firma del tratado, y duró hasta 1805 (Fernández Hernández, 1997, p. 160).

4 Hasta en el mismo ámbito de la capital, como consta en el balance negativo expresado por el impresor Ignacio Beteta de las causas de "la rusticidad y la especie de estupidez que hablando de los criollos ha pasado entre los escritores estrangeros como en proverbio" (Archivo General de Indias [AGI]: sección Estado, legajo 49, expediente 61, fecha: 22-01-1798).

5 Nombrado también Capitanía general, o Audiencia de Guatemala.

6 Nótese que, como en la mayoría de las sociedades de antiguo régimen, el fenómeno estuvo limitado a una porción ínfima de la población. interrogantes y propuestas de reforma sobre economía, sociedad, relaciones interculturales, en los límites de unas estructuras de poder laico y religioso tradicionalmente adversas al libre pensamiento y a la libre expresión.

Se dio, en la zona, una coyuntura muy peculiar de copresencia de individuos excepcionales en muchos aspectos. Procedentes de diferentes horizontes sociales, geográficos y académicos, les unía una notable ambición (e inquietud) intelectual y una preocupación por la mejora de su entorno, tanto local (fomento de la economía y la educación) como general (bien de la nación española y de la humanidad). Les unía también la convicción de que la prensa era llamada a desempeñar un papel clave en la elaboración y la transmisión de un saber práctico, eficaz, que no reñía con la valoración de la cultura escrita clásica y moderna. Del mismo modo que la consulta de libros en lenguas foráneas era concebida como un necesario nutrimento intelectual, se esperaba que cumpliera la misma función su puesta al alcance de los lectores mediante la traducción.

La traducción, en la tercera serie de la Gaceta de Guatemala (GG) (1707-1807), ${ }^{7}$ se presenta en múltiples modalidades. Su rastreo minucioso permite caracterizar el dinamismo intelectual de la región centroamericana. Si comparamos dicho dinamismo, aunque sea someramente, con producciones análogas de la época, es posible constatar que el enfoque traductológico permite también evaluar la aportación original del periódico (y sus límites) al tratamiento de los grandes tópicos que preocuparon las esferas cultas de las sociedades occidentales en los años cruciales del tornasiglo xVIII y XIX, años que corresponden al final del dominio incontestado de la Corona española en América y a

7 Una primera GG se publicó entre 1729 y 1731. A finales de siglo, el editor Ignacio Beteta retomó el título y sacó una segunda serie (1793-1796), cuyo programa fue "ampliado" en la que denominamos "tercera serie". Véase Poupeney Hart (en prensa). 
las primeras señales del ascenso político de la joven república del Norte.

Abordamos, pues, esta tercera serie de la GG desde una perspectiva traductológica, conjuntamente con el enfoque de los estudios coloniales. ${ }^{8}$ Luego de presentar las condiciones del proyecto editorial de la GG, analizamos las fuentes y referencias empleadas por los editores y colaboradores de este papel ${ }^{9}$ en diferentes idiomas (francés, latín, italiano e inglés). Seguidamente, describimos el oficio del traductor y sus diferentes intervenciones. Examinamos, por último, el discurso metatraductológico que se expresó en la GG y las diversas propuestas de los editores en el ámbito de la traducción.

\section{Las condiciones del proyecto editorial}

Como ya anticipamos, a mediados del último decenio del siglo XvIII, se dio en Centroamérica una serie de circunstancias que galvanizaron las energías de un pequeño grupo de literatos en torno al proyecto editorial de la GG. ${ }^{10} \mathrm{Sin}$ embargo, no faltaron los obstáculos. Los programas de reformas promovidos por la Corona española se tuvieron que realizar en un contexto de bloqueo marítimo, en el que las peripecias de los conflictos externos tuvieron un impacto particularmente negativo en la región, dada la dependencia de su economía en el monocultivo y el comercio del añil. Esta condición, unida al recrudecimiento de

8 El presente trabajo revisa y amplía un artículo publicado en la revista Target (Navarro y Poupeney Hart, 2019), en el que se precisan los planteamientos teóricos y metodológicos. Se inscribe dentro del marco de los estudios descriptivos de la traducción (Bassnett y Lefevere, 1990; Hermans, 1985; Toury, 1995).

9 Siguiendo la práctica de la época, usamos el término "papel" (i. e. "papel periódico") como sinónimo de periódico.

10 Preferimos la palabra "literato" a la anacrónica denominación "letrado", que el reconocido ensayo de Ángel Rama (1984) ha vuelto ubicua en el discurso crítico actual. En la época que nos toca, "letrado" designa exclusivamente al jurista. epidemias de viruelas, plagas de langostas y a la ausencia de vías terrestres de comunicación, provocó una situación de crisis para la que se investigaron soluciones, en particular en escritos extranjeros. Esta búsqueda se enfrentó con dificultades prácticas en la circulación de impresos, debido tanto al aislamiento geográfico de la región como al estatuto periférico del Reino con respecto a la circulación del saber, en cuanto dependencia de una potencia imperial en decadencia y apéndice de la Nueva España en aspectos económicos y culturales. ${ }^{11}$

Pese a las circunstancias apremiantes que vivía el Reino, estas no impidieron que una pequeña comunidad literata, vinculada en particular, pero no exclusivamente, con la Universidad San Carlos, se mantuviera atenta a las últimas ideas y publicaciones de los grandes centros occidentales. No impidieron que, desde 1797, las energías de los editores sucesivos de la GG no se concentraran solo en lo inmediato y lo local. Por el contrario, dado el contexto propicio y el carácter excepcional de su formación y sus ambiciones, los editores de la GG lograron mantener la vista puesta en referencias europeas y en la proyección transcontinental y transatlántica de sus propuestas.

Además del oidor criollo Jacobo de Villaurrutia (director de la GG hasta su salida a México en 1804), de su primer editor, el castellano Alejandro Ramírez (secretario del Consulado y más tarde del presidente de la Audiencia), y del editor de los últimos años de la GG, el asturiano Simón Carreño (conocido como "Simón Bergaño y Villegas", oficial de la Audiencia), en el círculo editorial se pueden mencionar personalidades influyentes y altamente respetadas en la élite centroamericana: dos catedráticos de la recién reformada Universidad San Carlos el franciscano fray José Antonio Goicoechea

11 Aunque no administrativos, como puntualiza el mexicano José Antonio de Alzate: "la provincia de Goatemala nunca se ha comprendido en la gobernación de Nueva España" (Gaceta de literatura I, 1831, p. 194). 
(criollo de Cartago) y el mercedario fray Mariano José López Rayón (criollo también)—, y el canónigo Antonio García Redondo (leonés), que actuaron como "Junta de Gaceta" durante la ausencia de Ramírez en 1799-1800. A estos nombres se tienen que añadir el del comerciante Juan Bautista Irisarri (navarro) y, en buena medida, el cirujano Narciso Esparragosa (criollo de Caracas), por no citar más que los principales. Coincidió esta circunstancia con la presencia fortuita en la región del cofundador del Mercurio Peruano - el periódico de mayor prestigio y difusión en la época colonial-, José Rossi y Rubí, en tanto alcalde mayor de Suchitepéquez.

La participación de estos personajes en el proyecto colectivo, que se deja entrever en la GG, es confirmada por documentación de archivos: esta contribuye a mitigar la dificultad de atribución de autoría, debida a la práctica casi sistemática del anonimato o al uso de seudónimos que, con algunas excepciones - Bergaño, en particular-, resultan difíciles de descifrar.

La lista de redactores para el periódico no se limita a estos nombres y acoge ministros de la Audiencia, miembros del clero, hacendados, comerciantes, grupos de vecinos, individuos del Reino o del virreinato vecino. Sin embargo, aún tomando en cuenta la variedad de las contribuciones, resalta a la lectura del papel la constancia de sus intereses y sus valores: más allá de la aplicación de un criterio coherente en la selección entre los textos recibidos para publicación, la impresión de continuidad en el propósito que anima la GG se debe a la abundancia de las notas editoriales que, en gran parte, logran canalizar la interpretación de las diversas propuestas.

Llama la atención el número considerable de obras foráneas citadas por unos y otros: su mención no significa que todas fueron consultadas en su integridad, ni mucho menos en su lengua original. Tampoco indica que circularan fuera de un exiguo círculo - por obvias razones, de miedo a la censura y afinidades - títulos de los que consta que fueron leídos. Recordemos también que mucha de la información cultural y técnica procedía de obras periodísticas, de enciclopedias y de otros tipos de compilaciones. Sin embargo, la consideración, bajo el ángulo muy preciso de la traducción, de diferentes modalidades de cita de obras foráneas ofrece un instrumento valioso para reconstruir el horizonte intelectual de una región del mundo hispano, en un período clave de la Historia, la víspera de las independencias en América.

El prospecto de la GG que se difundió a inicios de 1797 amplió explícitamente el programa del que se había hecho cargo el impresor Beteta en 1793. Las nuevas orientaciones confirmaban el interés local en el proyecto ilustrado de reforma de las provincias de la Monarquía española, promovido por la Corona, con el apoyo de las sociedades económicas de amigos del país. En el caso que nos ocupa, la iniciativa concreta partió de la Sociedad Guatemalteca (1795-1800), fundada por Jacobo de Villaurrutia y para la que la GG ampliada fue concebida como portavoz. En esta empresa, contaba el "autor" del papel con una experiencia como periodista adquirida durante su estancia en la península ibérica, ${ }^{12}$ y con el talento de su joven ayudante, Alejandro Ramírez, quien iba a actuar como editor.

Gracias a sus fuertes vínculos con la Sociedad, el impreso ofreció, en los primeros años, un diálogo alimentado por la colaboración de redactores de artículos originales: aunque no se limitaron a ellas, tomaron su inspiración de problemáticas regionales, enfocadas con entusiasmo según principios compartidos.

Una dinámica análoga había animado el otro gran periódico americano de la época, el $\mathrm{Mer}$ curio Peruano (1790-1795), ya mencionado. Sin

12 Concretamente, con el Correo de Madrid, del que afirma José Mariano Beristain que fue el principal autor (1821, III, p. 323), pero en el que queda todavía por averiguar el grado exacto de su participación. 
embargo, en contraste con el que fue modelo explícito de la GG, los editores de Guatemala cumplieron también, de forma complementaria, el mandato de proveer información puntual que les asignaba el título de "gaceta" y que heredaban de la segunda serie: se insertaron, por lo tanto, noticias del Reino (bandos, precios, plagas, nombramientos y defunciones, etc.), noticias del repetido conflicto con Inglaterra y del incremento del poder de Napoleón, además de noticias de Estados Unidos. Esto no quiere decir que se abstuviera de expresar un cierto rechazo respecto a esta faceta de la práctica periodística.

Había varias razones para ello, que tendrían una implicación directa sobre la selección de las temáticas abordadas y las fuentes aprovechadas y, por lo tanto, sobre la actividad traductiva en el periódico. A la escasez de noticias locales consideradas dignas de una amplia difusión ("Quando en el mercado no hay zanahorias, ¿como quiere Umd. que se vendan?"), ${ }^{13}$ se añadía la relativa cercanía de la Nueva España, que mantenía a las élites del Reino al tanto de la actualidad política y administrativa gracias a la Gaceta de México, leída también obviamente por la elevada porción de suscriptores novohispanos de la GG. ${ }^{14}$

Una vocación regionalista a ratos muy perceptible explica además, por otra parte, esta reticencia a insertar la retahíla de cápsulas de información europeas que caracterizan las llamadas "gacetas políticas". ${ }^{15}$ Concebida desde el inicio, ya lo dijimos, como órgano de la Sociedad económica, la tercera serie se quería promotora del conocimiento (interno y externo) del Reino y del fomento de su prosperidad, sin temor a recurrir a una tonalidad de reivindicación identi-

13 GG, v, 1801, núm. 212, p. 514.

14 Es lo que expresa sin ambigüedad el editor de Guatemala (x, 1807, núm. 476, p. 960).

15 Notemos que, a raíz de los dramáticos eventos desencadenados por la invasión napoleónica de la península ibérica, y después de más de un año de interrupción, es esta vocación, exclusivamente noticiosa, la más apta a canalizar el rumor público, la que dominará una cuarta serie de la GG (1808-1816). taria americanista y al uso ocasional de sociolectos típicamente centroamericanos.

A estos diferentes factores se añaden los efectos de otra vocación de la GG, que se podría caracterizar como sociocultural, ya que implica una estrategia de captación o retención de la atención de los lectores. Tal como proclama el editor del tomo IV, importa "deleitar à los lectores con la variedad de especies, y con lo que tenga algun aspecto de novedad" (GG, IV, $1800,179,350)$.

\section{Fuentes y referencias}

\subsection{Los medios del "deleite" y la "novedad", y las traducciones indirectas}

Para sostener el interés de los lectores, problema que la serie sacada por Beteta en 1793 no logró solucionar, la GG ampliada pudo disponer de contribuciones originales y muy variadas: informes, escritos satíricos, fábulas, composiciones poéticas, entre otras. Eran redactadas por corresponsales ocasionales, y sobre todo por los editores y por un pequeño círculo de colaboradores. El papel se nutrió también de la prensa periódica contemporánea y de libros clásicos y modernos, entre ellos, un buen número de obras extranjeras, consultadas en traducción y en su lengua original. Esto dio lugar a una actividad traductiva y reflexiva sobre la traducción, de la que solo un examen minucioso y sistemático de los textos puede revelar la amplitud.

El estudio de la prensa periódica temprana presenta una serie de obstáculos. El más importante, el acceso a los textos, está felizmente en curso de resolución, gracias a las operaciones de digitalización y puesta en línea llevadas a cabo por organizaciones e instituciones como Google Books, Internet Archives, Hathi Trust y bibliotecas nacionales. ${ }^{16}$

16 Véase Poupeney Hart (2017). 
Otro problema, relacionado de manera directa con el tema que nos ocupa, es el de la procedencia de los artículos: se trate de la autoría de los escritos concebidos localmente para el periódico, o que sean las fuentes de la información o de los textos expresamente citados, comentados y traducidos. El concepto de plagio (o "robo literario") estuvo presente en la conciencia de los editores de la GG, que manifestaron en varias ocasiones su desaprobación en cuanto a su práctica. ${ }^{17}$ Esto no impidió que la frontera con lo "ajeno" no fuera siempre respetada ni identificada de forma sistemática por el uso de caracteres ortotipográficos como las comillas. No impidió tampoco que muchos de los autores aprovechados no fueran claramente identificados.

El análisis del papel implica, por lo tanto, una labor detectivesca que no hubiera sido posible en la era predigital. El que esta rinda frutos inesperados no debe hacer olvidar que muchos de los resultados son de hecho hipótesis de las que solo se han aceptado las más probables en el presente trabajo, y que solo el tiempo e investigaciones ulteriores llegarán a completar, confirmar o refutar.

Bien es cierto que la calidad y la variedad de la actividad traductiva en el periódico conocieron modulaciones a lo largo de los 10 años de publicación de la tercera serie, en función del dinamismo y de la cohesión de los equipos editoriales y sus corresponsales más asiduos; de su dominio de lenguas extranjeras específicas; de su acceso a libros, y de su propia creatividad.

En cuanto a las noticias generales, por ejemplo, como era de esperar, la información del extranjero no era original y se sacaba sobre todo de la prensa en lengua española. Valiéndose de papeles como los peninsulares Correo Mercantil y Semanario de Agricultura, o la americana Gaceta de Mé-

17 Se puede citar, entre otros, el artículo titulado "Descubrimiento de un gran robo literario", redactado por el último editor (GG, x, 1806, núm. 435, pp. 793-795). xico, y sin mencionar sus fuentes en la mayoría de los casos, la GG insertaba las traducciones de noticias de eventos e invenciones en curso, publicadas inicialmente en otras lenguas europeas. Si bien se mantuvo relativamente constante el rubro de "Noticias de Europa", se nota que a la imprescindible Gaceta de Madrid, conseguida a través del correo de Oaxaca, se añadió como fuente principal la Aurora de la Habana, más polivalente que el periódico peninsular y accesible a finales de 1800 por vía marítima, alternativa a la ruta terrestre novohispana.

El acceso a las traducciones (y, por lo tanto, la inserción de traducciones indirectas) no se limitó a la prensa. La gran mayoría de los libros leídos en el Reino procedían de la península ibérica, donde se observó una intensa actividad traductiva a lo largo del siglo, con una recrudescencia notable en los años finales de la centuria (Checa Beltrán, 2016; García Garrosa y Lafarga, 2009). La élite se benefició plenamente de este fenómeno, y logró un acceso a la cultura impresa que no difería mucho de la experiencia de sus homólogos peninsulares y, tal vez, de muchas ciudades europeas de provincias. En España, el prestigio internacional de los literatos de habla francesa hizo que se consideraran prioritariamente sus obras a la hora de ilustrar o divertir el público: así se explica la disponibilidad de buenas traducciones al castellano de obras como "la celebrada historia natural de Buffon [...] la excelente física de los Arboles de Duhamel, y [...] el curiosicimo Espectaculo [sic] de la naturaleza de Pluche" (III, 1799, núm. 118, p. 89).

Por otra parte, dado el papel de intermediaria que la lengua francesa desempeñaba en la circulación del conocimiento, la mayoría de las obras escritas en otros idiomas europeos solían traducirse a partir de su versión gala: es el caso, citado en la GG, de los Elementos de medicina práctica del William Cullen, o las Reflexiones sobre la naturaleza de Christoph Christian Sturm. ${ }^{18}$

18 Véase el Anexo 1. 
Como se detalla en el Anexo 1 que adjuntamos a este artículo, encontramos así, en el periódico, un número importante de citas o menciones de traducciones de ensayos entre los más difundidos de Europa, con Gaetano Filangieri, François Fénelon o Adam Smith entre los múltiples autores aprovechados en su versión castellana. Hallamos también menciones notables a obras de referencia adaptadas de publicaciones francesas: entre otros títulos, el Diccionario de agricultura de François Rozier, el Diccionario de fisica de Mathurin Jacques Brisson, el Diccionario geográfico universal de Lawrence Echard, la Enciclopedia metódica, publicada por Antonio de Sancha (Donato, 1992).

\subsection{El acceso a obras originales}

En 1802, habiéndose enterado de la próxima publicación en París de un Diccionario de ciencias naturales (en francés), que anunciaba la colaboración de "Fourcroy, Jussieu, Lacepede, Dumont, Cuvier, Dumeril \&c. \&c.", el editor de la GG proclama que

Guatemala no serà la ultima ciudad de la America española à donde llegue èste libro útil [...] pues contamos con mas de un sabio, y no nos faltan aficionados, que se apresuraràn á solicitarlo, como ya sabemos que algunos lo han hecho (VI, 1802, núm. 278, p. 241).

Esta declaración confirma la presencia de una familiaridad con lenguas extranjeras en una porción no despreciable de la élite. Confirma, también, el dinamismo intelectual de este sector, y muy concretamente el papel de puente cultural que se asignan los editores entre la comunidad local y las altas referencias intelectuales.

Cuatro son las lenguas extranjeras de las que consta un conocimiento por lo menos pasivo entre los editores y colaboradores de la GG. Aunque no fue compartida en el mismo nivel por todos, no cabe duda de que esta comprensión del francés, del latín, del italiano y, en menor medida, del inglés, entre varios de los redactores, facilitó para el común de los lectores un acceso, aun superficial, a obras claves de la Ilustración europea.

\subsubsection{En francés}

Para el periodo que nos ocupa, "es un hecho incuestionable", escribe José Checa (2016), "que Francia sigue siendo para España intermediaria de la cultura europea" (p. 184) y, en América, como ya mencionamos, la GG no contradice esta tendencia. En el momento de evaluar la importancia del estudio de las "lenguas extrañas", si bien se recalca el interés de conocer el latín, el italiano y el inglés, insiste, por lo tanto, una de las contribuciones claves del periódico, ${ }^{19}$ en que, a pesar de la peligrosidad que se le achaca, ${ }^{20}$ se considere el francés como "un arca en donde se encierran riquísimos tesoros de la literatura" (GG, IV, 1800, núm. 186, p. 375).

Al contrario del italiano y del latín, es mínima la presencia concreta (citas) de la lengua francesa en el periódico. Sin embargo, aún tomando en cuenta el posible carácter superficial de la mención reiterada de autores que atestigua tanto el prestigio de las letras galas como la voluntad de la élite local de participar activamente en el debate intelectual internacional, hay constancia de que muchas obras fueron leídas en francés, incluyendo escritos en otros idiomas europeos que fueron consultados en su traducción al francés. Algunos de ellos fueron resumidos o vertidos parcialmente al castellano en la GG: es lo que se observa con títulos como las Observations d'un voyageur del viajero alemán Abel Burja, la Harmonie des Psaumes et de l'Évangile del abate Pluche, el Voyage dans

19 Se trata de un "Sueño", protagonizado por D. Farruco, probable alter ego de Jacobo de Villurrutia (Iv, 1800, núm. 186, pp. 375-376).

20 Le declara su interlocutor a D. Farruco que "el entender la lengua francesa es ahora algo peligroso", refiriéndose a los temores que suscitaron las ideas filosóficas sospechosas de haber provocado la Revolución francesa (IV, 1800, núm. 186, p. 375). 


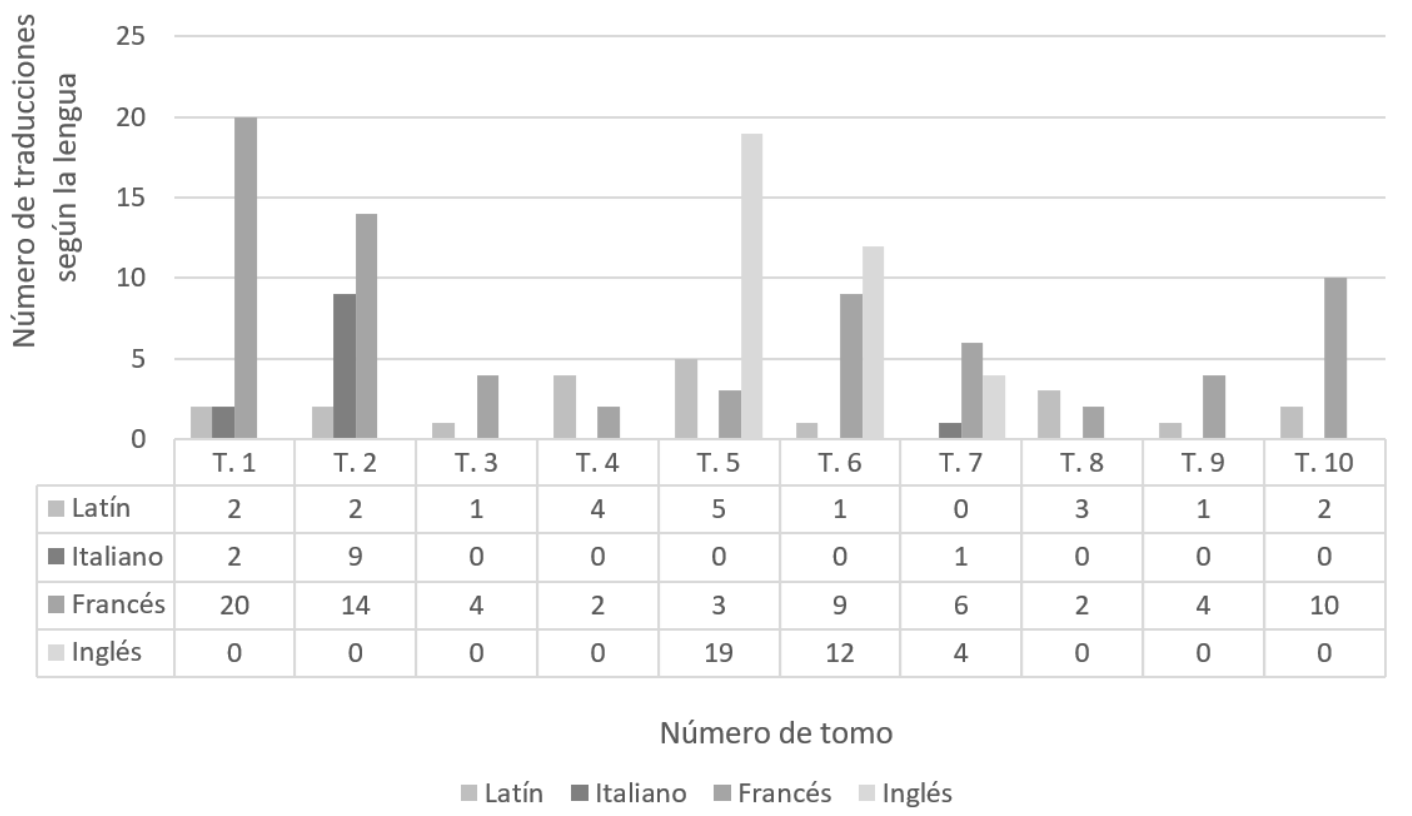

Figura 1. Traducciones directas en la Gaceta de Guatemala (según las lenguas del texto fuente)

l'hémisphère austral, et autour du monde de James Cook, las Lettres américaines del conde Carli.

Por otra parte, se ofrecen también traducciones (breves o más amplias) de obras publicadas originalmente en francés. Comparada con la de otras lenguas, su frecuencia es alta y relativamente constante en el periódico (véase Figura 1), ya sean pasajes de enciclopedias, diccionarios o recopilaciones (incluyendo el Journal de physique de François Rozier, ${ }^{21}$ la Encyclopédie méthodique, o el "precioso Diccionario de Hombres ilustres, digno de traducirse al castellano" de Honoré Lacombe de Prézel (x, 1806, núm. 457, p. 881), o que sean numerosos extractos de libros para los que no existían traducciones, por razones de dificultad del texto, de falta de mercado, o de censura: entre ellos, pasajes de La Bruyère, D'Alembert, Fontenelle o de Etudes de la nature de Bernardin de Saint Pierre, caracterizado este como "un libro útil, que tiene la felicidad de ser superior à la esfera de los traductores del baratillo, y que por éso sin duda no se ha vulgarizado" (II, 1798, núm. 52, p. 27).

21 Se conoce por este nombre el papel titulado Observations sur la physique, sur l'bistoire naturelle et sur les arts.
Estos títulos debieron circular entre bibliotecas privadas. Es lo que insinúa la mención en la gaceta de obras de Massillon, de la Lógica de Condillac, del Telémaco de Fénelon, y de los Mélanges amusants des saillies d'esprit de Lesage, entre las obras guardadas en el baúl del joven (ficticio, pero verosímil) interlocutor de un corresponsal (viII, 1804, núm. 340, p. 28).

\subsubsection{En latín}

Aparte del francés, otra lengua extranjera por la que se interesaba el "autor" de la GG (Villaurrutia) era el latín, lo que le llevó a traducir, "perfeccionar" y publicar en 1801 el "precioso curso de latinidad" (Iv, 1801, núm. 192, p. 399) de Ignace Vanière.

No podía faltar esta dimensión lingüística en una ambiciosa publicación como la GG, dado su carácter de lengua usada en ámbitos tanto sagrados como científicos, y debido al peso de la tradición grecorromana en la educación superior, y el prestigio de sus letras entre las élites. Así, abundan las referencias a personajes y obras de la Antigüedad europea que, en la tradición del discurso clásico, actúan como figuras tutelares 
que autorizan el discurso. ${ }^{22}$ Lo expresan sin ambigüedad estas palabras de introducción de un artículo sobre "Comercio":

No hay asunto de que mas hablen los hombres ni en que mas hierren que el de sus intereses. Las pruebas mas palmarias de ésta antiquisima observacion de Plauto se encontrarán en el extracto que vamos à hacer de una carta escrita desde Mexico, fecha 26 de Agosto de 98 (III, 1799, núm. 97, p. 1).

O esta mención, en la que los calificativos refuerzan la idea de un patrimonio intelectual común:

Al celebre Valerio honraron los Romanos con el sobre nombre de Publicola, por aquella famosa ley con que afianzó su libertad; y yo que procuro a mis compatriotas uno de los mayores bienes de la sociedad, qual es el que tengan algua propiedad territorial [...], no he sacado otra cosa que rasguños y mogicones [...] (III, 1799, 130, 135; énfasis nuestro).

En cuanto a la misma lengua latina, se trata también de un conocimiento compartido con una buena proporción de los lectores, lo que explica la alta frecuencia de expresiones sin traducción que se insertan generalmente entre comillas o en cursiva, en muchos de los ensayos, a lo largo de los diez tomos de la serie. Ocupan un lugar preeminente en epígrafes o motes, pero se salpican también los artículos con expresiones o frases breves, sin traducción, relacionadas directa o indirectamente con el tema tratado.

La práctica, común entre los literatos de la época, denota confianza en la presencia de una comunidad selecta de lectores que no se sentirá alienada. Constituye también un mecanismo elitista de consolidación de un círculo erudito, masculino y mino-

22 Se mencionan o citan a Aristóteles, Cicerón (Tulio), Crates, Demóstenes, Diodoro de Sicilia, Diógenes Laercio, Dioscórides, Galeno, Herodoto, Hipócrates, Homero, Horacio, Juvenal, Licurgo, Luciano, Lucilio, Lucrecio, Ovidio, Persio, Píndaro, Platón, Plauto, Plinio, Plutarco, Quintiliano, Séneca, Sócrates, Suetonio, Tácito, Terencio, [Tito] Livio, Virgilio. ritario en términos socioeconómicos, que no deja de contrastar con el llamado muy horizontal a colaboraciones de parte de "hombres de ideas, de cualquier nacimiento, de cualquiera clase", con el que los editores de la tercera serie anunciaron su programa en el "Prospecto de ampliación" (GG, I, feb. 1797).

Sin embargo, al lado de estas notaciones y referencias clásicas que se mantienen a lo largo de la publicación, se deja oír una fuerte corriente crítica hacia el uso del latín en la formación académica y en la difusión del saber, a la que se une, en una oportunidad, la voz de una (supuestamente) corresponsal, Lucindabela, quien ve abierta una invitación a tomar la pluma, y si bien no a expresar sus ideas (no ha llegado el momento todavía), por lo menos a "exponer [sus] sentimientos” (III, 1799, núm. 136, p. 161).

Paradójicamente, los mismos autores que recurren a citas y referencias en latín sin traducción son los que lo critican como lengua vehicular del saber. No obstante, esta contradicción no merece comentario en la GG y, a pesar de los ataques, sobresale la fascinación por la lengua y sus producciones como fuente de prestigio para quien las cultiva, y como inspiración intelectual, espiritual y poética. ${ }^{23}$

Ofreciéndose implícitamente como término medio, varios textos abogarán por una mayor sistematicidad en la traducción de importantes referencias latina. Se inserta así, en el tomo Iv, una traducción del himno de Prudencio a san Lorenzo, que va acompañada de la expresión de una preocupación por el respeto de un ideal de fidelidad y efectividad: "Traducidos estos versos, sugetandonos á todo el rigor del sentido, y aun á la fuerza gramatical en lo posible dicen asi", y luego se disponen los versos en dos columnas (IV, 1800, núm. 173, p. 326).

Culmina esta preocupación con la versión que da Simón Bergaño de una epístola de Ovidio (fragmento del Libro v de los Tristia) y que abarca un número entero, con su comentario (x, 1806, núm. 462,

23 Tenemos un claro ejemplo de ello al principio de un artículo sobre el celibato, con la cita en latín de un pasaje de Hecyra de Terencio, seguido de una traducción libre al castellano y una referencia completa a la obra (II, 1797, núm. 29, p. 225). 
pp. 901-904). El último editor de la serie confiesa sentir una afinidad muy particular con la temática del exilio y del amor frustrado, y se esmera por expresar el potencial de la obra, "perfeccionando" una traducción ya existente:

Sin ser tan buen poeta como Ovidio, la poesia y el amor tienen en mi alma un imperio tan fuerte como en la suya; y las circunstancias en la que me hallo son tan conformes á la de Ovidio, que me han movido á traducir èsta pieza, robando el tiempo al desahogo de mis propias ideas. Mr. Mercier en su Bonnet de nuit, tomo primero, tradujo ésta epistola en prosa francesa; pero con demasiada libertad. [...] (x, 1806, núm. 462, pp. 901-904).

\subsubsection{En italiano}

En cuanto a la "lengua toscana", se considera reiteradamente uno de los tres idiomas modernos cuyo estudio contribuye a "la perfeccion del hombre sabio" (IV, 1800, núm. 186, p. 376), y su lugar en la GG es a la vez difuso y variado.

Se evocan los nombres de Filippo Baldini, el marqués Caracciolo, Antonio Genovesi, Lorenzo Ganganelli. Se mencionan obras traducidas al castellano, como las Reflexiones sobre el buen gusto en las ciencias y en las artes de Luis Antonio Muratori o la Historia crítica de la vida civil, de Vincenzo Martinelli. Se incluyen referencias bibliográficas y traducciones parciales de obras disponibles en francés (las Lettres américaines de Carli), u originales: los Opuscoli sopra il lusso y Dell'amore verso la patria del conde Giambattista Roberti, sin olvidar la edición italiana, La dottrina degli azzardi, del matemático Abraham de Moivre. ${ }^{24}$ Se insertan también

$24 \mathrm{El}$ recurso a esta obra ilustra bien la tendencia en la GG de no señalar claramente las fronteras entre el contenido original y los pasajes traducidos o parafraseados (con comillas, en particular). El lector se queda con la impresión de que se privilegia la fluidez de la exposición, lo que implica intervenciones en el texto original. En lo que difiere de la mayoría de la citas, que sean traducciones directas o indirectas, es en la precisión de la referencia bibliográfica: "En el excelente libro de Abraham Moivre, titulado: Doctrina de las casuali- expresiones en lengua original (el " $E$ chi troppo assotiglia, si scavezza" de Petrarca, el "io sono anché pittore", atribuido a Correggio, o el "Or son cangiati modi, son mutati costumi... O voy felici, / che viveste in quel secolo !' del poeta renacentista Antonio Ongaro), sin traducción, como guiños al lector culto sobre la base de que la "inteligencia [del italiano] se facilita mucho en poseiendo el latín" (IV, 1800, núm. 186, p. 375).

En los últimos años ha habido un esfuerzo por identificar la presencia de la ilustración italiana en el pensamiento político de finales del siglo XVIII y principios del XIX en el mundo atlántico. ${ }^{25}$ Entre los autores resaltados no podía faltar el nombre de Gaetano Filangieri, miembro de la "insigne escuela napolitana de Economía política del siglo XVIII" (Astigarraga, 2007, p. 2). El número de ediciones que conoció su Scienza della Legislazione y la presencia de la obra en bibliotecas americanas, públicas y privadas, atestiguan su éxito (Morelli, 2006, p. 435). El que no aparezca citada en la GG no es tan sorprendente, sin embargo, dada la presencia en el "Indice de libros prohibidos" por Roma, tanto del texto original como de su versión edulcorada en la traducción al castellano por Jaime Rubio. En estas circunstancias, solo un rastreo particularmente fino del periódico permitiría apreciar el impacto real de sus propuestas en los círculos cultos centroamericanos.

El tomo II de la GG ofrece, sin embargo, una constancia irrefutable del acceso, por lo menos parcial, a la obra monumental del jurista italiano. El artículo "Educación" (II, 1799, núms. 66, 69, 70), firmado por M.A.C.R., integra literalmente, y sin identificarlos como préstamos ni nombrar al autor, largos segmentos

dades, aplicada à los problemas de la probabilidad de la vida, de las pensiones vitalicias Etc. traducido al italiano por el Padre Roberto Gaeta, monge Cisterciense, de que hemos sacado las especies de que vamos hablando, se cuentan [etc.]" (I, 1797, 26, 207).

25 Véanse, en particular, Astigarraga (2007), Morelli (2006) y Rodríguez García (2012). 
del "Prólogo del traductor" del libro Iv (vol. v), dedicado "a las leyes relativas a la educación, costumbres e instrucción pública". ${ }^{26}$

Entre otras referencias que también reproduce en parte el artículo, cita Jaime Rubio unos "pensamientos" del filósofo Favorino. Vuelven estos a aparecer tal cual bajo la pluma de quien fue, sin la menor duda, el ministro de la Audiencia, Manuel Antonio del Campo y Rivas. El editor, por su parte, introduce un comentario que se puede interpretar como velada acusación de copia hacia el poderoso oidor, al observar que, por contraste, "algunos autores de mérito" [en este caso, Rubio], "a quienes no conviene la nota de plagiarios, [...] han renovado [los pensamientos de Favorino] en nuestros días" (II, 1798, núm. 70, p. 179). Esta observación apunta a una familiaridad con la obra de Filangieri que va más allá de un simple individuo.

Donde sí se cita abiertamente al autor original, y donde la aportación de la GG es imponderable, es en la inserción de amplios pasajes de la Storia antica del Messico (Cesena, 1781), del jesuita novohispano Francisco Javier Clavijero. Se trata de la primera traducción en castellano después de la también parcial versión de Antonio Sánchez Valverde para la América vindicada de la calumnia de haber sido madre del mal venéreo (1785).

Gracias a los trabajos bibliográficos de Francisco Aguilar Piñal (1981) y Pilar Martino Alba (2013), tenemos una buena idea de la actividad traductiva de Jacobo de Villaurrutia a partir de dos lenguas: el francés y el italiano. Notemos, en particular, su edición de "varias pláticas que pronunció" el arzobispo de Florencia, don Antonio Martini, "en su iglesia Catedral" (1801), que denota un aprecio de la lengua toscana y un interés en la práctica de la traducción: ¿no declara, en la "Advertencia" de la Instrucción sobre el misterio de la Eucaristía como sacrificio, su seudónimo 'Jaime Villa López' "que se à puesto el mismo esmero, para conservar en la pureza de nuestro idioma la cla-

26 Jaime Rubio, "Prólogo del traductor" en Cayetano Filangieri, Ciencia de la legislación (1789). ridad, fluidez, gravedad, sencillez magestuosa y energia del original" (1801, p. 2)? ¿Habrá sido, entonces, él el traductor de Clavijero? ¿Habrá supervisado el trabajo de Ramírez o coordinado un esfuerzo colectivo? ¿Habrá tenido alguna contribución en la operación el milanés de origen José Rossi y Rubí? Son preguntas que tememos queden sin respuesta.

\subsubsection{En inglés}

La presencia del inglés como lengua traducida en la GG es sumamente limitada, tanto en el tiempo de la publicación como en términos de competencia, en el seno del equipo de redacción y sus corresponsales. Esto no quiere decir que no se valorara la aportación de un autor anglosajón clásico como Francis Bacon, que se cita a partir del latín, y otros más modernos, a los que simplemente se menciona o se cita a partir de versiones en francés o en castellano: es el caso de Adam Smith, en particular.

Sin embargo, no se puede minimizar la importancia del impacto de una comisión que efectuó Alejandro Ramírez como representante del negociante Juan Bautista Irisarri, en el contexto del reajuste hispano al bloqueo británico del tráfico transatlántico. ${ }^{27}$ Este encargo le llevó por el Caribe hasta Baltimore y Filadelfia, donde los contactos que estableció contribuyeron a que fuera elegido, poco después (1801), corresponsal de la American Philosophical Society, la más antigua sociedad académica del país (Shafer, 1958, p. 260). Tenía 24 años. Durante su ausencia (1799-1800), el primer editor de la tercera serie fue reemplazado por una "Junta de Gaceta", y a su regreso aprovechó su domi-

27 Se había autorizado el comercio con barcos de potencias neutrales en noviembre de 1797 , pero el anuncio de la revocación del permiso (abril de 1799) tardó varios meses en llegar a Centroamérica. Ramírez ya había salido y se mantuvo en pie su papel de intermediario en la compra y el flete de mercancías. Regresó a la capital a principios de 1801, desde el puerto de Trujillo, punto de contacto con muchos barcos mercantes procedentes de Estados Unidos. 
nio de la lengua, así como su acceso a nuevas fuentes de información, para ampliar los horizontes de los lectores: son varias las referencias a "gazetas" o "papeles ingleses" o "gazetas de Filadelfia" en los tomos v (1801), vi (1802) y, en menor medida, VII (1803).

Sin embargo, la traducción directa no se limita solo a las noticias. Es particularmente notable la inserción, en el periódico, de versiones del inglés, inéditas en español y francés, que se concentran en los mismos tomos. Hablamos de obras de publicación reciente, como las famosas Remarks Concerning the Savages of North-America de Benjamin Franklin (1784), de las que se traduce con mucho esmero, pero sin identificar a su autor, un fragmento intitulado "Hospitalidad de los indios mohawks". O todavía más reciente: dos trabajos médicos, las memorias sobre el bocio, de Benjamin Smith Barton, y sobre las viruelas, de Charles Rochemont Aikin (1800). Se ofrecen también, sin identificar su procedencia, pasajes del ensayo traducido al inglés como Outlines of a Philosophy of the History of Man (1800) de Johan Gottfried Herder, ${ }^{28} \mathrm{y}$ en una tonalidad más festiva, del relato de las aventuras de George Hanger (1801) (véase Anexo 1).

\section{El oficio de traductor}

\subsection{El anonimato}

Desde los primeros tiempos de la prensa periódica como proveedora de información procedente de horizontes lejanos, "los traductores eran los

28 Si bien se identifica como "un filósofo alemán" al autor de un extracto sacado de "un libro reciente" (vI, 1802, núm. 241, p. 1), se incorporan sin comillas más pasajes de este mismo libro (VI, 1802, núm. 246, p. 40 y núm. 247, p. 45). Dos semanas después se ofrece un fragmento más amplio de la obra como traducción "del Aleman” (vi, 1802, núm. 249, pp. 53-55). Dada la ausencia de la menor prueba del conocimiento de esta lengua en el círculo de la GG, lo más probable es que la traducción se haya basado en la edición en inglés de Herder (única existente en otro idioma europeo en aquel momento). personajes principales de [las] primitivas redacciones" (Durand, 1983, pp. XIX-XXI). La actividad se siguió desarrollando de forma anónima; la misma transparencia de la comunicación de la información era una clave del éxito de una empresa fundamentalmente práctica. Esta invisibilidad del traductor, asociada con el frecuente anonimato de la autoría de los artículos originales, ha tendido a ser una característica del medio hasta nuestras fechas. ${ }^{29}$

No siendo una publicación meramente noticiosa, la GG ofrece un cuadro un poco más complejo, dado que su vocación, en gran parte literaria - es decir, en los términos del "Prospecto de ampliación", referida "à las letras, a las ciencias, a los estudios" (GG, I, feb. 1797)-, requiere en general que se le pueda asignar un origen individualizado y, por ende, una autoridad, a la palabra citada (Aristóteles, Bacon, Plinio, Buffon, Brown, etc.).

La precisión bibliográfica era un requisito explícito de las leyes (Urzainqui, 1995, p. 201), que constituyó un marco de referencia, si bien no se respetó estrictamente en la prensa peninsular ni en la americana. Desde el punto de vista del periodismo ilustrado, responde también a un ideal editorial de claridad y rigurosidad, encarnado con cada vez mayor escrupulosidad a lo largo de la serie.

Ya desde el tomo i se van mencionando títulos de obras comentadas o extractadas: "Viages de Chard. Cap. 7", "Hist. gen. de los viages Tom. xxI", "Roberti, Opusculi sopra il Lusso. Bassano, 1785", o "In Hispanis Bibliothecis (decía en otro tiempo Daniel Morhosio en su Polyhistor)". ${ }^{30}$

Adicionalmente, en varias ocasiones se completan las coordenadas bibliográficas con el nombre del traductor al castellano:

29 Varios autores han abordado la invisibilidad del traductor en la prensa, entre ellos, Bielsa y Bassnett (2009), Hernández Guerrero (2005), Valdeón (2010) y Van Doorslaer (2010).

30 Respectivamente: I, 1797, núm. 3, p. 19; núm. 14, p. 108; núm. 16, p. 122; núm. 33, p. 264. 
[...] las adiciones de sus traductores los señores D. Juan de Arribas y Soria, y D. Julian de Velasco $[\ldots]$

[...] el tratado de la conservacion de la salud de los pueblos, traducido al castellano por D. Benito Bails [...]

[...] como lo hace en el Prologo a la traduccion del Frances al Castellano de Triunfos de la verdadera religion contra los extravios de la razon en el conde de Valmont el R.P.F. Clemente Millana [...] [...] Condorcet. Compendio de Smith, traducido por el Caballero Yrujo [...]

[...] Ensayos \&c. escritos en frances por el Dr. Colon, y traducidos por el Dr. Francisco Piguillem, de la Academia de Medicina de Barcelona. - Origen y descubrimiento de la Vaccina \&c. también traducido por el Dr. Pedro Hernández, médico de Madrid [...]. ${ }^{31}$

Pasa lo mismo, en el ámbito local, con el nombre del traductor de un libro del que la GG hace la promoción: se cita repetidamente a 'Jaime Villa López', seudónimo, ya lo vimos, de Jacobo Villaurrutia, para los Rudimentos de gramática latina de Vanière.

Se conserva, en cambio, el anonimato, por lo menos inicialmente, para las traducciones realizadas en el seno mismo de la GG: no sorprende que sea el caso con las noticias dispersas recogidas de periódicos extranjeros, pero la reticencia afecta también los textos más amplios y "literarios".

Esta dinámica, afín a la tonalidad impersonal del periodismo, dará un vuelco en los últimos tomos del papel con Simón Bergaño, y la consolidación de una posición editorial que irá acompañada de su creciente aislamiento y la ausencia de colaboradores dispuestos a alimentar el papel con contribuciones originales.

\subsection{Intervenciones deliberadas y (auto) censura}

A lo largo de la tercera serie, el uso de expresiones como "traducción literal", "traducción

31 Respectivamente: I, 1797, núm. 39, p. 310; II, 1790, núm. 50, p. 13; III, 1800, núm. 150, p. 193; VI, 1802, núm. 253, p. 8; VII, 1803, núm. 290, p. 11; VII, 1803, núm. 297, p. 72. libre", "resumen" y "extracto" manifiesta la conciencia de que diferentes tipos de relación con los textos fuentes responden a circunstancias y exigencias propias. En ocasiones, se resalta y se valora explícitamente la literalidad en las traducciones. Ejemplo de ello es la noticia titulada "Güegüechos" (v, 1801, núm. 229, pp. 587-590), donde el editor afirma que traduce "literalmente" el artículo.

En otras ocasiones, las traducciones en la GG se alejan voluntariamente de la literalidad según modalidades variadas. En primer lugar, una de estas "intervenciones deliberadas" (Bastin, 2007, p. 40) en el proceso de traducción consiste en la introducción de notas explicativas y comentarios, en el cuerpo del texto o al pie de página. El editor de la GG, lejos de ser entonces un agente pasivo, toma parte en el proceso traductivo, con el objeto de aportar informaciones, sobre el texto fuente, sobre las condiciones de producción de la traducción o sobre el contexto original de la noticia que se traduce. ${ }^{32}$

En segundo lugar, un redactor o el mismo editor interviene en el proceso de traducción cuando hace del texto fuente una traducción parcial, es decir, en la que partes del texto fuente han sido resumidas (resumen) u omitidas (fragmento). ${ }^{33}$ En una tendencia constante en la serie, los redactores afirman ser muy "escrupulosos en omitir las menudencias inútiles" (III, 1799, núm. 100, p. 15), es decir, en suprimir información repetitiva, poco interesante para su lector o carente de fundamentos.

En tercer lugar, las intervenciones del traductor también se materializan por medio de la omisión de las fuentes o su tergiversación. De 1797 a 1807, si bien la GG menciona, a menudo sin cita ni comentario, más de 200 apelli-

32 Tal es el caso del artículo "Politica. Continúa el articulo de los numeros precedentes. De la Rusia" (I, 1797, núm. 3, p. 18), donde el editor explica en nota al pie el término "Boyard", diciendo: "Así se llaman los Grandes en Rusia".

33 Por ejemplo, en un artículo sobre noticias de Europa, el editor comenta que se han recibido varias gacetas de Filadelfia y que "[e]xtratar[á] lo mas importante" (v, 1801, núm. 214, p. 522). 
dos de autores extranjeros modernos (véanse Anexos 1 y 2), coexiste paradójicamente este fenómeno de name dropping con la falta, en momentos claves, del nombre del autor que se comenta o se cita, y con el recurso eventual a perífrasis y falsas atribuciones. Para la mayoría de los casos, la hipótesis de un descuido o una ignorancia no se justifica, y se plantea, por lo tanto, la pregunta del impacto de la censura (y de la autocensura) en los autores y editores.

En consonancia con la política francesa de limitación de la libertad de expresión, ${ }^{34}$ la Corona española buscó mantener un control férreo sobre una prensa de la que se esperaba que se ciñera a la comunicación de los programas oficiales y a las informaciones económicas prácticas. A esto se añadieron otros tipos de restricciones, nacidos de la imposición de un orden tradicional (político, social, intelectual, espiritual, lingüístico, genérico) particularmente rígido.

En el caso del Reino de Guatemala, además de la censura ejercida desde el Ministerio de Gracia y Justicia, y la Presidencia de la Audiencia sobre el proyecto editorial y cada número individual, se añaden las restricciones generales impuestas por la Inquisición. ${ }^{35}$

Documentación de archivo deja constancia también de las presiones represivas ejercidas por el regente Ambrosio Cerdán y Pontero y el arzobispo Luis de Peñalver y Cárdenas, ambos portavoces de las corrientes más conservadoras de la pequeña comunidad de ascendencia europea. ${ }^{36}$

34 Esto, en contraste con la política británica, en la que la garantía proveída por la Constitución favoreció la emergencia y la expansión de una prensa periódica particularmente dinámica, tanto en la metrópoli como en sus colonias americanas (Doyon, 2002, p. 4).

35 Véase Chinchilla Aguilar (1999) para el caso de Guatemala, y más generalmente Lafarga (2004), quien subraya, por otra parte, la inocuidad de varios dictámenes inquisitoriales, por lo menos en la península ibérica.

36 Véanse, por ejemplo, las representaciones ante la Corona del regente Cerdán (AGI: Guatemala 515,
Por otra parte, la ausencia de coordinación entre las instituciones provocó incoherencias, lo que permitió, por ejemplo, que el mismo Villaurrutia pudiera fungir como juez de imprentas, y García Redondo y Goicoechea como censores del papel.

El análisis de las prácticas de cita y traducción de obras extranjeras en la GG permite resaltar con exactitud estas incoherencias, nacidas de las tensiones entre las diferentes instancias detentoras del poder.

La GG hace así un eco discreto de la existencia de varias modalidades de censura, que están directamente ligadas a la gestión del periódico o son más generales. En ambos tipos de situación, los editores se empeñan prudentemente en minimizar las restricciones, como consta en una observación de que

Hay muchos libros extrangeros en todo genero de literatura que pueden y deben traducirse, y que bien traducidos serían muy útiles á nuestra juventud: muchos verdaderamente clásicos en francés y en italiano, no pocos en inglés, y algunos en aléman. Exceptuemos el inmenso farrago de novelas, de que está inundado el mundo [...]. El Gobierno acaba de prohivir la traduccion de tales escritos ... En que predicando virtud, corruccion enseña (VIII, 1805, núm. 379, p. 565).

Desde el inicio de la publicación, llama la atención la familiaridad de los varios articulistas con textos objetos de la censura inquisitorial: desde los inevitables Helvétius, Montesquieu, Mably, Condillac, Voltaire y Rousseau, hasta las poesías de Iglesias, Cadalso y Young. Son menos obvios, pero sí consistentes, los mecanismos a través de los que se revela, oculta o tergiversa la referencia en función de las circunstancias del momento y otras consideraciones que quedan por investigar.

En cuanto a la traducción misma de textos foráneos (que sea directa o indirecta), la GG

núm. 117, 1802) y del arzobispo Peñalver (agi:

Guatemala 649, núm. 7, 1806). 
manifiesta una variedad de prácticas que contribuyen a definir cierto margen de libertad. Sin embargo, dada la extrema limitación de cualquier expresión de disconformidad en el mundo hispano, sería excesivo enfocarlas como "transgresivas" (Delisle, 2014, p. 44).

La omisión del apellido del autor del texto fuente, unido o no al recurso a la perífrasis, es sin duda la medida más empleada: "cierto escritor del siglo XVII" (para La Bruyère, III, 1799, núm. 106, p. 40), "un escritor extrangero" o simplemente "un escritor" (para Rousseau, I, 1797, núm. 44, p. 352; II, 1798, núm. 58, p. 82), "un celebre francés" o "cierto autor bien conocido" (para Raynal, IV, 1800, núm. 146, p. 176; VII, 1803, núm. 331, p. 440). Pero como ya anticipamos, no se trata de un fenómeno sistemático: Montesquieu, designado como "un hombre celebre" o "uno de los escritores mas celebres de este siglo" (I, 1797, núm. 5, p. 35 y núm. 9, p. 68), es identificado explícitamente en otra ocasión del mismo tomo (I, 1797, núm. 3, p. 20). Igual pasa con Rousseau, nombrado en el tomo Ix (1805, núm. 388, p. 613), mientras se había ocultado su nombre en años anteriores, como autor de un breve pasaje de L'Émile traducido en el tomo I (1797, núm. 44, p. 352).

Por una parte, no se puede negar que esta práctica de omitir la fuente directa entra en contradicción con la preocupación por autorizar el discurso respecto de interlocutores locales $\mathrm{y}$, muy particularmente, internacionales, cuyo reconocimiento es una meta importante del papel. Por otra, como se ve en la puesta en escena de un joven pedante que actúa como si "en Neuchatel hubiera tomado cafe con el famoso Suizo [1eer: Jean-Jacques Rousseau], y apostillado su Pacto Social" o "hubiera asistido en Ginebra a la representacion del Mahoma, y co- mentado ésta tragedia en los entreactos con su mismo autor [leer: Voltaire]" (II, 1798, núm. 55, p. 53), las alusiones buscan reforzar una complicidad muy propicia al éxito del proyecto, y a la consolidación de redes, entre el periódico y el lector, quien se sentirá orgulloso de haberlas descifrado.

Con el objeto de evitar una posible censura del artículo o del número entero, los editores de la GG recurrieron a lo que podría denominarse "falsas atribuciones". En el tomo vi (1802, núm. 267) nos encontramos, por ejemplo, con la situación curiosa de un pasaje atribuido explícitamente a Jean-Baptiste Duhalde, autor de una Description géographique, historique, chronologique, politique et physique de l'empire de la Chine et de la Tartarie chinoise (1735), pero sacado de hecho de una nota de Claude Adrien Helvétius en el controvertido ensayo De l'Esprit (1754).

Vemos, en otro caso de falsa atribución, que proponemos nombrar "desvío", cómo se aprovecha una lectura extranjera sin proveer la referencia. En este ejemplo, se coloca el texto bajo la tutela de una autoridad clásica, citada en el texto original. Así, otra vez, Helvétius aparece borrado en la traducción:

Un caso similar lo ofrece la eliminación de la referencia al abate Gabriel Bonnot de Mably, autor del pasaje siguiente, en beneficio único de Platón:

En estos casos, más allá de un simple mecanismo para aligerar el texto, bien puede tratarse de una tentativa de limitar las referencias a autores sospechosos de disconformidad con el orden establecido y, por lo tanto, se busca evadir la crítica y la denuncia de parte de los miembros más reaccionarios de la pequeña élite criolla.
En un diálogo de Luciano: "Mi primera morada, dice la Filosofía, no la tuve en Grecia. [...]" ¿ Por qué la Filosofia ha pasado de la Grecia à la Hesperia, de la Hesperia à Constantinopla y à la Arabia? (GG, I, 1797, núm. 4, p. 28)
Dans un dialogue de Lucien, "Ce n'est point en Grèce, dit la Philosophie, que je fis ma premiere demeure [...]" Pourquoi la philosophie a-t-elle passé de la Grece dans I'Hespérie, de l'Hesperie à Constantinople \& e Arabie? [...] (Helvétius, De l'esprit, Discours III, Chap. XXVII) 
[...] no quería [Platón] que su republica se estableciese cerca de la mar, ni a la orilla de algun rio considerable. Esta posición, dice (1) la expondria a los peligros del Comercio [...]

(1) Dialog. Sob. La Justicia. Lib. III (GG, I, 1797, núm. 5, p. 35)
Je ne puis m'empêcher de penser à Platon, qui, pour assurer le bonheur d'une république, voulait qu'elle ne s'établît point sur les rivages de la mer, ou sur les bords d'une grande rivière. Cette position, dit-il, l'exposerait aux dangers du commerce (Mably, Observations sur le gouvernement et les loix des Etats-Unis d'Amérique, Lettre Iv)

\section{Modalidades y funciones de la traducción}

En contraste con el Mercurio Peruano, que la GG se fijó como norte desde el "Prospecto de ampliación", un aspecto particularmente 1lamativo del papel centroamericano es la presencia de traducciones que abarcan gran parte de uno o varios números, y que elegimos llamar, de manera tentativa, "integrales", porque se presentan al lector como tales, aunque no correspondan, en todos los casos, a un conjunto claramente circunscrito y autónomo en el texto fuente. ${ }^{37}$

Estos escritos están inmersos en una dinámica de lectura en la que la traducción no está al servicio de una información o una argumentación, sino que presupone una atención específica del consumidor, en continuidad con la práctica generalizada en los sectores literatos occidentales de morceaux choisis para uso privado y publicación. Esta condición de "piezas escogidas", como las denomina Bergaño (GG, X, 1806 , núm. 459 , p. 889 ), no deja de afectar positivamente la calidad de la expresión y va con frecuencia acompañada de un metadicurso que revela una preocupación auténtica por la operación traductiva, sobre la que volveremos.

Se pueden considerar más particularmente bajo este rubro de "traducciones integrales" las ya mencionadas secciones de la Storia antica del Messico de Francisco Javier Clavijero, otras de Remarks de Franklin, de la memoria de Barton sobre el bocio, del Tratado sobre la vacuna de Aikin, así como fragmentos de Ideen

37 Se encuentra una lista de estos textos en el Anexo 3. zur Philosophie der Geschichte der Menschheit de Herder, ya mencionado. A estos textos habría que añadir un discurso del filósofo antiguo $\mathrm{Fa}$ vorino, traducido quizá a partir del francés, y el que pronunció Buffon al ingresar a la Academia francesa.

Finalmente, bajo la pluma de Simón Bergaño, único autor en reclamar la dignidad de traductor, encontramos una versión de la epístola de Ovidio, también citada anteriormente, así como discursos y breves ensayos sacados del Conservateur ou Bibliothèque choisie de Littérature, de Morale et d'Histoire de Antoine-François Delandine, del Génie de M. de Buffon, publicado por Giovanni Ferry de Saint Constant, y de Mon Bonnet de nuit de Louis-Sébastien Mercier (véase Figura 2).

Si bien el objetivo de muchas de las traducciones breves es la información, lo más inmediata posible y, en algunos casos, la legitimación del discurso, a la manera de citas de autoridad, el de los textos más largos es inevitablemente más variado: informativo, por supuesto, pero también fático, lúdico, poético, identitario, por retomar las clásicas propuestas de Roman Jakobson (1967), combinándolas con las de Jean Delisle (2003).

La vocación de servicio del bien público de la GG justifica plenamente, por ejemplo, la inclusión del trabajo de Barton, dada la presencia de bocio endémico en la región, como lo recalcó muy gráficamente Thomas Gage en su famoso relato de viaje. Cabe destacar, sin embargo, que más allá de esta función informativa (o referencial, en la terminología de Jakobson), llama la atención la elección del término local de "güegüechos" en la traducción, en vez de "paperas", 


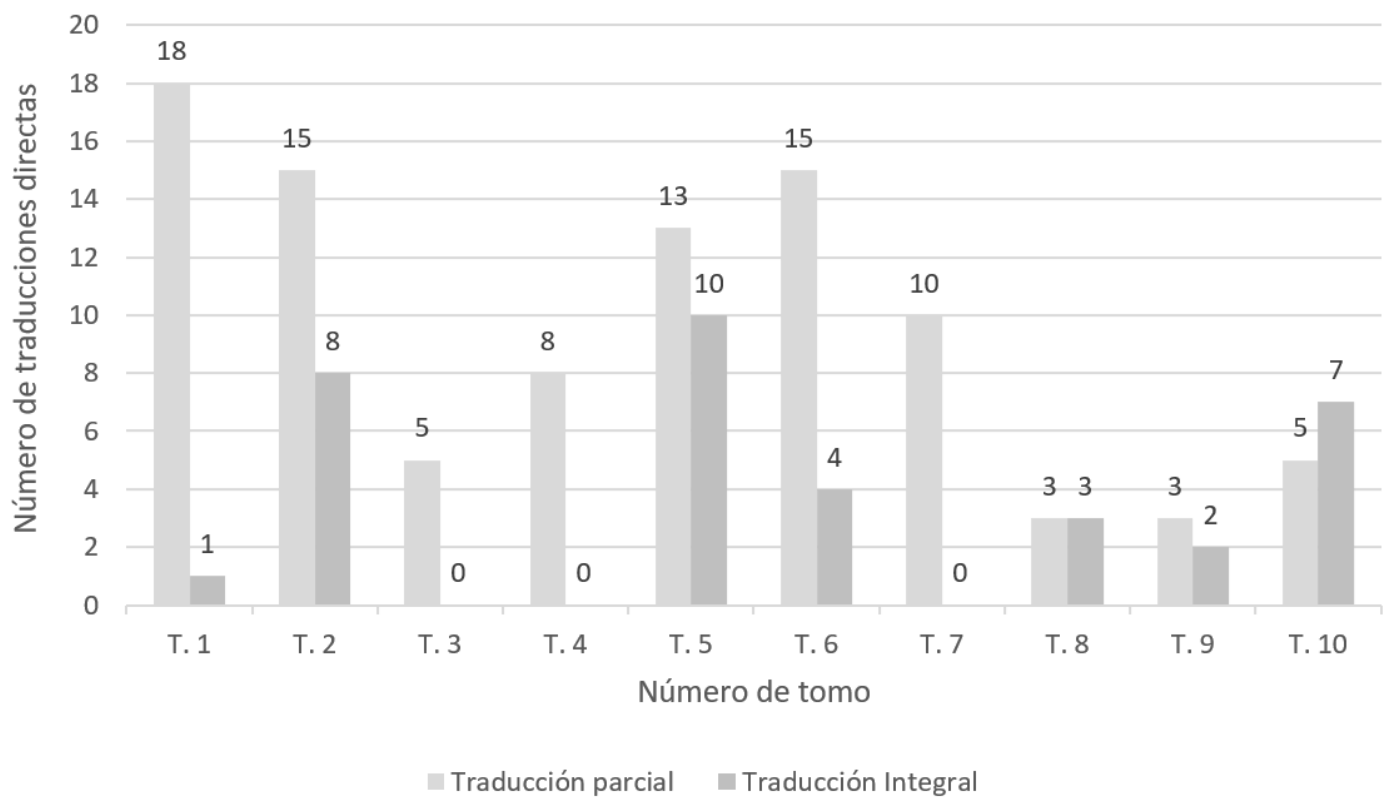

Figura 2. Traducciones directas en la Gaceta de Guatemala (parciales e integrales)

usual en castellano (v, 1801, 210). En las mismas circunstancias, en el reino vecino de Nueva Granada, el naturalista José Celestino Mutis había recurrido también a un localismo en sus "Reflexiones sobre la enfermedad que vulgarmente se llama Coto": lo había señalado como tal ("vulgarmente") y había limitado su uso al título y la introducción, prefiriendo el vocablo más general de "tumor". ${ }^{38}$ En la GG no sucede esto, puesto que dicho término es retomado una y otra vez, tanto en el tomo I, bajo la pluma del médico Dr. José Flores (núm. 16), como en el II, en la traducción de un fragmento del viaje de Gage (núm. 69) y, por último, en el v, con el informe de Barton.

El fenómeno se explica a primera vista por la necesidad de llegar lo más directamente posible a una porción no literata del público, participante en las lecturas colectivas o públicas que caracterizaban el consumo de la prensa en el Antiguo Régimen. Sin embargo, su uso exclusivo (en detrimento de sinónimos como paperas o tumor, perfectamente comprensibles para

38 Papel periódico de Santa Fe de Bogotá, 1794, núm. 137, pp. 669-676. En Rodríguez (1978). cualquier oyente hispanohablante) se podría interpretar también como parte de un reclamo identitario americanista.

Recuerda lo anterior otro caso de uso de un término regional, marcado también por una etimología autóctona: la "chichigua". La lactancia materna es uno de los temas favoritos de los debates públicos tanto en Europa como en la América ilustrada, y no podía faltar en la GG, donde se encuentra tratado en dos ocasiones que involucran el recurso a la traducción del discurso del filósofo Faborino "sobre la obligacion en que están las Madres de criar por sí mismas á sus hijos" (tomos II y IX).

En el primer artículo, firmado con las iniciales M.A.C.R. (Manuel Antonio del Campo y Rivas), el autor intenta mantener una distancia con el término de "güegüecho", para el que da la explicación de "deformidad de escrofulos, vulgarmente llamados cotos, o güegüechos" (II, 1798, núm. 69, p. 174). Manifiesta esta misma voluntad de distancia con el vocablo "chichigua", que introduce comentándolo como "nodrizas, o amas de leche, conocidas aquí vulgarmente 
con las voces indicas de Chichiguas" (II, 1798, núm. 66, p. 149), y que usa alternándolo con sinónimos.

Mientras la contribución del oidor Campo y Rivas revela ser, como ya señalamos, un plagio del prólogo a la Ciencia de la legislación de Cayetano Filangieri, el propio editor de la GG (Alejandro Ramírez) nos informó, en una nota, que había estado trabajando en una versión integral del mismo discurso, probablemente con el ánimo de ofrecer "una traduccion al castellano tan ajustada y tan nerviosa como la hecha al frances por Mr. L'Abbé de V... (E.)" (II, 1798, núm. 69, p. 172).

Es, sin duda alguna, esta misma traducción de Ramírez, quien descartó publicarla en su momento para evitar redundancias, la que reaparece en el tomo IX, siete años después, y reafirma la dignidad del vocablo local de "chichigua". En nota al pie, el editor comenta: "Permitasenos el uso de esta voz, que és propia y privativa del pays en que vivimos, á beneficio de la claridad.- Equivale á Nodriza" (IX, 1805, núm. 391, p. 626). La inclusión del Discurso de Faborino, lejos del contexto de denuncia de "vicios de la educación doméstica" que caracterizó los primeros años de la GG, parece ahora cumplir primordialmente otra función: la de relleno. Función "fática", en específico propicia en un momento en que, si bien protegido por un Ramírez ya influyente en la Audiencia gracias a su posición de secretario de Cámara y Gobierno, el último editor de la gaceta se encuentra particularmente aislado, sin corresponsales regulares que alimenten el periódico. La situación no mejorará con el tiempo, y no cabe duda de que este mismo papel lo cumplirán, en los meses finales de la tercera serie, los "ensayos traducidos de diferentes autores, en calidad de piezas escogidas, que irán embelleciendo nuestra gazeta" (x, 1806, núm. 459, p. 889).

Movido por este fin, Bergaño retoma autores prestigiosos: ya sea Buffon o Louis-Sébastien
Mercier, con cuyo talento se mide en la traducción de Ovidio en verso, mientras el francés la había dado en prosa. Deja la impresión de que estas operaciones son para él también un modo de acrecentar su capital simbólico, dentro y fuera de las fronteras del Reino. Es muy probable que resultara acertado el cálculo, ya que completan, con una tonalidad internacional y con el aporte adicional de una reflexión metadiscursiva, la figura de miembro de la República de las letras que, por otra parte, se construyó con la inserción de sus propias poesías en la GG.

\section{Discurso sobre la traducción}

En contraste con la península ibérica, donde recuerda otra vez José Checa (2016) que "durante todo el siglo xviii se discutió sobre la oportunidad de traducir al español obras extranjeras" (p. 178), abundan en la GG las señales de aprecio incondicional de esta práctica. Un aprecio que expresa un corresponsal novohispano, particularmente prolífico y valorado por los editores, el licenciado Mateo Zorrilla, cuando escribe:

Los traductores aún cuando no sean de los más puntuales, se hacen dignos de la estimación de la gente agradecida, por que con riesgo de perder su crédito, su trabajo y su dinero hacen sudar a las prensas españolas con obras clásicas extranjeras, que suplen la carencia total de muchas de las nacionales para su necesaria instrucción (III, 1799, núm. 118, p. 89).

Se mide ciertamente este aprecio en el recurso a múltiples traducciones, tanto en la transcripción de noticias periodísticas como en la cita de obras ya publicadas. Se mide de forma palmaria, desde el primer año de la serie, en la solicitud, emitida por un grupo de suscriptores — sin duda — novohispanos, de tener acceso al pasado de su patria a través de una versión en castellano de las disertaciones de Clavijero. Se medirá, por tomar otro ejemplo, con la difusión de un tratado sobre la vacuna, en un momento de preocupación agudizada por la presencia de epidemias de viruelas en la región, 
en el contexto de una actividad traductiva que se intensificará al final de la serie.

A pesar de la distancia, son varios los testimonios de que los editores y sus corresponsales más asiduos estuvieron al tanto de los debates que animaban la esfera pública peninsular en torno a la oportunidad y la calidad de las traducciones: ${ }^{39}$ el vocabulario que emplean y las referencias a las que recurren, en particular, lo dejan bien claro. ${ }^{40}$ Están al tanto también de la preocupación por el doble peligro potencial en la traducción de libros en francés: la corrupción de la lengua (debida a la introducción de galicismos), y la de las buenas costumbres y los buenos pensamientos, por influencia de los llamados "filósofos" ${ }^{41}$ No son, sin embargo, estos los aspectos que sobresalen a la lectura del periódico, sino, más bien, el interés, por no decir el entusiasmo, por el patrimonio compartido que representan estas vías de acceso a varias dimensiones de la experiencia humana (social, moral, científica, médica, económica, estética, etc.).

El que se reconozca la utilidad de las traducciones no quiere decir, sin embargo, que no se ponga en tela de juicio su eficacia. En un caso particularmente llamativo, se llega a cuestionar la misma esencia de la operación traductiva. El episodio se sitúa en el segundo tomo

39 Véanse, en particular, Checa (2016), Lafarga (2004) y Pajares Infante (1996).

40 Expresiones como "traductores de baratillo", “idioma genízaro y mestizo" (II, 1798, núm. 52, p. 27) se encuentran, por ejemplo, a un lado y otro del Atlántico.

41 El licenciado Zorrilla asocia, muy sintomáticamente, estas dos amenazas, en su argumentación a favor de la creación de "unas quantas plazas de expertos traductores [...] como atalayas": "Esta providencia [...] excusaría el peligro inminente que corren muchos de contaminarse en maxîmas contrarias à la Religión, y a la Politica. Porque yo conozco à hartos $[. .$.$] preciados del lenguaraces,$ que la mitad de lo que leen comprenden al reves, y la otra mitad traducen chapuceramente" (IV, 1801, núm. 190, p. 391). de la serie, donde el autor, F.M.J.L.R. (López Rayón), ${ }^{42}$ plantea los términos de lo que resulta ser una preocupación central del papel: la de los medios que facilitan la comunicación del saber (la posibilidad de una "lengua universal" o la prensa periódica misma) y sus obstáculos.

El mercedario introduce, traduciéndola, una reflexión de Bonaventure Noël d'Argonne, que traza un panorama amplio y documentado de las limitaciones de la práctica de traducción. Enumera "Natal Argonense" las condiciones necesarias, aunque prácticamente inalcanzables, para lograr ser un buen traductor: que 1) "conozca plenamente la lengua del autor que traduce, y aquella en que intenta dar la traducción"; 2) "perciba a fondo las materias que trata su autor" (II, núm. 89, p. 318); y 3) logre "transformarse en la persona de aquel cuya obra traduce, que no parezca sino que una sola alma anima los dos cuerpos" (326). No se satisface el artículo con la inevitable conclusión de "la imposibilidad de una exactísima traducción" (II, núm. 91, p. 326). Sin embargo, deja abierto el debate, al contraponer a la opinión del cartujo la del benedictino Feijoo, partidario del abandono del estudio de las lenguas muertas (el griego, en particular) y, por lo tanto, favorable a las traducciones.

En pocas, pero notables ocasiones, como la del texto de López Rayón, la GG dedica un lugar específico a reflexiones sobre la actividad traductiva. Otro caso lo constituye un "discurso" firmado por D.A.R. (probablemente Alejandro Ramírez), ${ }^{43}$ en el que se reafirma sin ambigüedad el imperativo de proponer al público versiones (fiables) en castellano: remite directamente al debate peninsular, al declarar que

Dijo Cadahalso [sic] que prescindiendo de lo que se ha adelantado en fisica y matemáticas, no nos hacen absoluta falta las traducciones. Dijo mal aunque se ciña su proposición a los libros de

42 En la sección Estudios, II, 1798, núms. 86, 89 y 91.

43 "De los libros clásicos. Y de sus traducciones" (GG, VIII, 1805, núms. 380-381). 
extrangeros modernos. Por lo de buen Español, ni Cadahalso ni hombre nacido me echa el pie delante. Yo amo mi patria como el que mas, amo sus buenos escritores, y con ellos me deleito. [...] Pero amor no quita conocimiento. El verdadero amor de la patria consiste en procurar sus ventajas, y no en alavarla tontamente (VIII, 1805, núm. 381, pp. 564-565).

Continúa recalcando que "hay muchos libros extrangeros en todo genero de literatura que pueden y deben traducirse, y que bien traducidos serian muy útiles a nuestra juventud" (1805, núm. 381, p. 565). Como se puede constatar, el criterio que domina aquí (y en el resto de la serie) es el pragmático, lo que lleva el autor del artículo a proponer la creación de una "academia de traductores", no en el sentido institucional de la que no llegó a crearse en la península ibérica (Lépinette, 1997, p. 8), sino en uno más modesto: el de un programa de formación. ${ }^{44}$

Una intervención (tal vez apócrifa) de suscriptores había marcado, desde el primer tomo, la pauta de lo que sería la práctica traductiva en la GG. Ya mencionamos una solicitud, acompañada de "cinco firmas": que se encargara el periódico de ofrecer una "traducción o un extracto sólido y menudo de las disertaciones" que, desde su exilio italiano, el "docto ex-Jesuita" Clavijero escribió sobre la historia antigua de México y no tuvo más remedio que publicar en "lengua toscana".

Llaman la atención las pautas que asignan los corresponsales a los editores de "traducir a la letra, sin alteración ni modificación" unos "párrafos" expresamente señalados (GG, I, 1797, núm. 27, p. 214). A la seriedad del reto ("sobre lo qual le encargamos la conciencia"), responde un compromiso de la GG en los mismos términos: "empeñamos nuestra palabra de complacer à estos suscriptores" (GG, I, 1797, núm. 27, p. 214, nota). Este cuidado por respetar, dentro de lo posible, la letra del tex-

\footnotetext{
44 Véase Navarro y Poupeney-Hart (2019,
} pp. 15-16). to original, y tomar en serio (a conciencia) todo el proceso, informará en el periódico la mayoría de las operaciones de traducción. Se manifiesta en múltiples ocasiones y se la recuerda al lector como una de las misiones que se asigna el periódico. Leemos así, en la introducción de la sección "De la curación y prevención", de la traducción del tratado de Barton sobre el bocio (güegüechos):

Este articulo és corto; y asi por esto, como por ser el demas interés, o por lo menos el que se ha solicitado con mas impaciencia, le traduciremos literalmente; bien á nuestro pesar sin embargo, pues tememos que no llene las esperanzas, en particular de los pacientes ( $v, 1801$, núm. 229, p. 587).

No cabe duda de que este comentario se relaciona con el código deontológico que vemos perfilarse a lo largo de los años y que se manifiesta también en la condena reiterada del plagio y la preocupación por proveer referencias precisas, limitada sin duda por el contexto de censura.

Un comentario de pie de página, por el traductor del discurso sobre el estilo de Buffon, es un testimonio elocuente, si bien discreto, del grado de reflexión que acompaña la práctica traductiva en el pequeño círculo de editores-redactores del periódico. Versa sobra la noción de equivalente literal, en este caso de "desarrollo" con respecto al término francés développement:

$\left.{ }^{*}\right)$ Hay palabras que pueden pasar en una traduccion, y no en un discurso original. Una de ellas és ésta, que el uso va recibiendo como equivalente literal de la francesa développement. Quando se traduce debe conservarse, en quanto es compatible, el giro de los periodos del autor extraño, para no desviarse mucho de su caracter, ni debilitar sus pensamientos.Quando se escribe originalmente, suponiendo formado el estilo por los modelos de la lengua, deben los pensamientos acomodarse á su índole y giro peculiar; lo que no es dificil al buen escritor, ni el encontrar siguiendo éste camino las palabras más propias y castizas para expresarse con elegancia y 
nervio, en ningun caso inferior á otra de las lenguas vivas (VIII, 1804, núm. 370, p. 484).

Esta cita capta, en pocas palabras, una problemática fundamental en la práctica traductiva, relacionada con la noción de equivalencia, tan discutida entre los literatos europeos de la época (y discutida, todavía en la actualidad, entre los traductólogos). Por otra parte, subraya también el traductor la importancia de producir un texto elegante en la lengua meta, lo que deja entrever otro de los temas de discusión que tenía lugar en los círculos europeos: sobre si algunas lenguas vivas poseían más recursos discursivos que otras, y si esto afectaba directamente la calidad (y la posibilidad) de la traducción.

Es muy posible que el autor de esta observación, "Servidori", sea de hecho el editor Simón Bergaño. Lo cierto es que dará un giro particularmente dinámico a la operación: al mismo tiempo que varios comentarios sobre el proceso, ofrece, efectivamente, el mayor número de traducciones originales en la GG, a pesar de que, nos dice él, "ejerz[a] este oficio con harta repugnancia: tiene demasiado amor propio para sugetarse con gusto a la qualidad mercenaria, y material / de traductor de lenguas" (x, 1806, núm. 459, p. 889). Su motivación puede resultar muy circunstancial - la falta de colaboradores asiduos-, y meramente personal -el interés en mejorar su conocimiento del francés-, pero aquí también prima la preocupación por el servicio del bien público que anima el proyecto de la GG desde sus inicios. ${ }^{45}$

45 Es lo que expresa claramente una nota al pie de página: “[...] el deseo de perfeccionarse en este exercicio para poder imponerse bien en las obras extrangeras [...] le ha movido a traducir y escribir á un mismo tiempo, persuadido de que este es el mejor medio de tomar un perfecto conocimiento á cerca de las diferentes indoles, frases é idiotismos de los idiomas." Continúa: "Por otro lado, quiere que todas sus vigilias tengan alguna relación no solo con su deseo de saber, sino también

\section{Conclusión}

La reflexión sobre la traducción se inscribe inicialmente en el contexto de una preocupación por la difusión del conocimiento, $y$ más precisamente por el acceso a las "nuevas especies y descubrimientos" procedentes tradicionalmente de Europa (II, 1798, núm. 86, p. 297). Expresa una conciencia aguda del estatuto periférico de la provincia centroamericana, lo que explica las declaraciones defensivas del tipo "también nacen en Guatemala Tulios" (I, 1797, núm. 10, p. 75) o "[en Guatemala] contamos con mas de un sabio" (VI, 1802, núm. 278, p. 241)", ya citada.

Esta preocupación por participar plenamente en la comunicación del saber explica la cantidad de referencias eruditas europeas o angloamericanas, ya sea traducidas o solo mencionadas. Explica, asimismo, las numerosas intervenciones de los autores en contra del latín como lengua de enseñanza, así como el interés, manifestado por la pequeña élite ilustrada del Reino, en las discusiones europeas sobre la posibilidad de una lengua universal (II, 1798, núm. 86) y sobre la traducción.

Lo que revela el examen tanto de la abundante actividad traductiva, de las múltiples menciones bibliográficas, como de las reflexiones sobre la traducción son profundas concordancias entre esta olvidada provincia de la Monarquía española y las preocupaciones y las referencias de la metrópoli, o aun las de regiones consideradas mucho más avanzadas del mundo occidental. Esto se debe a la energía de un grupo exquisito, a su compromiso social, a la emulación propiciada por la existencia de un nuevo medio, la prensa periódica, que facilita compartir ideas, recibir estímulos y tener planes (o, por lo menos, tener la ilusión de poder planificar) para el futuro.

con la utilidad publica [...]” (x, 1806, núm. 459, p. 890). 


\section{Referencias}

Aguilar Piñal, F. (1981). Bibliografia de autores españoles del siglo XVIII (Tomo VIII). csic.

Alzate y Ramírez, J. A. [1788-1795] (1831). Gacetas de Literatura de México. 4 vols. Manuel Buen Abad.

Astigarraga, J. (2007). La Ilustración napolitana imputada. Críticas y censuras a la Scienza della Legislazione de G. Filangeri en la España de finales del siglo xviII. Nuevo Mundo. Mundos Nuevos. Colloques. https://doi.org/10.4000/ nuevomundo.6911

Bassnett, S. y Lefevere, A. (Eds.) (1990). Translation, history and culture. Pinter Publishers.

Bastin, G. L. (2007). Histoire, traductions et traductologie. En G. Wotjak (Ed.), Quo vadis Translatologie? Ein halbes Jahrhundert universitäre Ausbildung von Dolmetschern und Übersetzern in Leipzig (pp. 35-44). Frank \& Timme.

Beristain de Souza, J. M. (1821). Biblioteca hispanoamericana septentrional (Tomo III). Oficina de Alejandro Valdés.

Bielsa, E. y Bassnett, S. (2009). Translation in global news. Routledge.

Checa, J. (2016). El debate literario-politico en la prensa cultural española (1801-1808). Vervuert.

Chinchilla Águilar, E. (1999). La Inquisición en Guatemala. Universidad de San Carlos de Guatemala.

Delisle, J. (2003). L'histoire de la traduction. Son importance en traductologie, son enseignement au moyen d'un didacticiel multimédia et multilingue. Forum, 1(1), 1-16. https://doi. org/10.1075/forum.1.2.01del

Donato, C. (1992). L'Encyclopedia metodica: la traduction espagnole de l'Encyclopédie méthodique. Recherches sur Diderot et sur l'Encyclopédie, 12, 155-164. https://www.persee.fr/doc/ rde_0769-0886_1992_num_12_1_1165

Doyon, N. (2002). Le rôle de la presse périodique au Bas-Canada tel que présenté dans les prospectus : assurer la postérité de la nation canadienne. UQAM. https://www.yumpu.com/fr/document/ view/16697119/nova-doyon-le-role-de-lapresse-periodique-au-bas-uqam
Duhalde, J. B. (1735). Description géographique, historique, chronologique, politique et physique de l'empire de la Chine et de la Tartarie chinoise. Le Mercier.

Durand, J. (1983). Prólogo. En Gazeta de Lima de 1793 a junio de 1794 (pp. 11-57). COFIDE.

Fernández Hernández, B. (1997). El gobierno del intendente Anguiano en Honduras (1796-1812). Universidad de Sevilla.

García Garrosa, M. J. y Lafarga, F. (2004). Estudio preliminar. En El discurso sobre la traducción en la España del siglo XVIII: estudio y antología (pp. 2-91). Reichenberger.

Helvétius, C. A. (1754). De l'Esprit. Le Mercier.

Hermans, T. (1985). The manipulation of literature: Studies in literary translation. St. Martin's Press.

Hernández Guerrero, M. J. (2005). Prensa y traducción. En C. Cortés Zaborras y M. J. Hernández Guerrero (Ed.), La traducción periodística (pp. 155-173). Ediciones de la Universidad de Castilla-La Mancha.

Jakobson, R. (1967). Essais de linguistique générale. Minuit.

Lafarga, F. (2004). El siglo xviII, de la Ilustración al Romanticismo. En F. Lafarga y L. Pegenaute (Eds.), Historia de la traducción en España (pp. 209-319). Ambos mundos.

Lépinette, B. (1997). La historia de la traducción. Metodología. Apuntes bibliográficos. LynX Documentos de Trabajo, 14, 1-24. http://www. histal.net/wp-content/uploads/2011/08/ La-historia-de-la-traduccion-metodologia-apuntes-bibliograficos.pdf

Mably, G. B. de. (1784). Observations sur le gouvernement et les loix des Etats-Unis d'Amérique, par Mr. L'Abbé de Mably. Amsterdam.

Martino Alba, P. (2013). Jacobo de Villaurrutia y López de Osorio (1757-1833). Jurista. DOM/ MX/es/GT. En Grupo de Investigación HISTRAD (Ed.), Biografias de traductores. HISTRAD Universidad de Alicante. https://web.ua.es/ $\mathrm{va} / \mathrm{histrad} /$ documentos/biografies/jacobo-de-villaurrutia.pdf

Morelli, F. (2006). Tras las huellas perdidas de Filangieri: nuevas perspectivas sobre la cultura política constitucional en el Atlántico hispánico. Historia Contemporánea, (33), 435-436. 
Navarro, A. y Poupeney Hart, C. (2019). Translating from/for the margins of empire. The Gaceta de Guatemala (1797-1807) and the enlightened elites. Target, 31(2), 207-227. https://doi. org/10.1075/target.19093.nav

Pajares Infante, E. (1996). La teoría de la traducción en el siglo XvIII. Livius, (8), 165-174. https://dialnet.unirioja.es/servlet/articulo?codigo $=171320$

Poupeney Hart, C. (2017). La prensa temprana en la era digital: contexto y recursos. Ístmica, (20), 129-146. https://doi.org/10.15359/istmica. 20.8

Poupeney Hart, C. (2021). Gaceta de Guatemala in the colonial period. En The Oxford Research of Latin American History. Oxford University Press. https://doi.org/10.1093/acrefore/9780199366439.013.916

Rama, Á. 1984. La ciudad letrada. Ediciones del Norte.

Rodríguez García, M. E. (2012). La Ilustración posible en la Lima setecentista: debates sobre el alcance de las Luces en el mundo hispánico. En J. Damião Rodrigues (Ed.), O Atlântico revolucionârio. Circulação de ideias e de elites no final do antigo regime (pp. 323-346). СHAM.
Rodríguez, M. del S. [1791-1797] (1978). Papel Periódico de Santa Fe de Bogotá. Banco de la República-Biblioteca Nacional.

Rubio, J. (1779). Prólogo del traductor. En C. Filangieri, Ciencia de la legislación (Tomo v, pp. xlvii-xcviii). Imprenta de Manuel González.

Shafer, R. J. (1958). The economic societies in the Spanish world. Syracuse University Press.

Toury, G. (1995). Descriptive translation studies - and beyond. John Benjamins.

Urzainqui, I. (1995). Un nuevo instrumento cultural: la prensa periódica. En J. Álvarez Barrientos, F. López y I. Urzainqui (Eds.), La república de las letras en la España del siglo xviii (pp. 125-216). CSIC.

Valdeón, R. A. (2010). Translation in the informational society. Across Languages and Cultures, 11(2), 149-160. https://akjournals.com/view/ journals/084/11/2/article-p149.xml

Van Doorslaer, L. (2010). Journalism and translation. En Y. Gambier y L. van Doorslaer (Eds.), Handbook of translation studies (pp. 180-184). John Benjamins.

Vanière, I. (1801). Rudimentos de gramática latina. Primera parte del curso de latinidad. Escrito en francés por Mr. Vanière. Simplificada por el traductor D. Jaime Villa Lopez. Ed. Beteta.

RT: Retraducción

T: Traducción

TF: Texto fuente

Tr: Traducción indirecta

$\mathrm{T}^{*}$ : Traducción en la que las referencias de la GG no coinciden con las fuentes disponibles, o de la que no hay seguridad de que se trate de una traducción directa o indirecta 


\section{Anexo 1. Obras modernas citadas o traducidas $^{46}$}

Accarias de Sérionne, Jacques [ANI]. Historia de los intereses de comercio de todas las naciones de Europa. En GG, Atribuido al traductor Domingo de Marcoleta. En GG, vI, 1802, núm. 273 [M].

Aikin, Charles Rochemont. Jennerian discovery, or a concise view of all the most important facts that have hitherto appeared respecting the cow pox. En GG, VI, 1802, núms. 277, 279, 281 [E,T].

Almeida, Theodoro de. El hombre feliz, independiente del mundo, $y$ de la fortuna, 1785. En GG, II, 1798, núm. $94[\mathrm{M}]$.

Almeida, Theodoro de. Recreación filosófica o diálogo sobre la filosofia natural. En GG, VIII, 1804, núm. $340[\mathrm{M}]$.

Anderson, Adam. [ONI: An historical and chronological deduction of the origin of commerce from the earliest accounts to the present time]. En GG, VII, 1803, núm. 309 [E].

Anson, George. A voyage around the world, in the years 1740, 1749. En GG, II, 1798, núm. 81 [Co, E].

Argonne, Noël. Traité de la lecture des Pères de l'Église ou Méthode pour les lire utilement. En GG, II, 1798, núms. 86, 89, 91 [т, Co].

Arnaud, François-Thomas de Baculard. Les épreuves du sentiment. En GG, VIII, 1805, núm. 381 [M].

46 Se indican tentativamente las versiones consultadas por autores de la GG. No se han tomado en cuenta las gacetas y otros tipos de periódicos proveedores de información. Además de la dificultad de averiguar la fuente exacta de las noticias, se habría alargado demasiado la lista de los textos consultados y aprovechados.

Como consta en la abundancia de las notaciones “ANI" u "ONI", una proporción considerable de textos traducidos aparece sin referencia de autor y obra citada. Esto contradice las condenas reiteradas de la práctica del plagio en la GG. Es probable que otras razones, además del temor a la censura, hayan estado en juego: el descuido, el acceso a apuntes y textos fragmentarios y, más generalmente en la época, una concepción poco arraigada de la propiedad intelectual.
Ayres Ramos de Silva de Sá, Matías [ANI]. Reflexiones sobre la vanidad de los hombres. En GG, VIII, 1804, núm. 367 [Co].

Bacon of Verulam, Francis. Historia vitce et mortis. En GG, IV, 1800, núm. 171 [E].

Bacon of Verulam, Francis. Novum organum scientiarum. En GG, II, 1798, núm. 49 [T*].

Bacon of Verulam, Francis. [ons: De officio judicis]. En GG, II, 1798, núm. 63 [Cita].

Bacon of Verulam, Francis. [ons: Novum organum scientiarum], en Étienne Bonnot de Condillac [ANI]: [ons: Cours d'études pour l'instruction du Prince de Parme]. En GG, vI, 1802, núms. 269, 270, 271 [т].

Bacon of Verulam, Francis. [ons: Novum organum scientiarum]. En GG, I, 1797, núms. 13, 39 [E, $\mathrm{Co}$.

Bacon of Verulam, Francis. [ONI]. En GG, VI, 1802, núms. 246, $256[\mathrm{M}, \mathrm{T}]$.

Barruel, Augustin [ANI]. Les Helviennes, ou Lettres provinciales philosophiques. En GG, IX, 1805, núm. 414 [M].

Barton, Benjamin Smith. A Memoir concerning the Disease of Goitre as it Prevails in Different Parts of North-America. En GG, v, 1801, núms. 210, $211,213,216,218,221,224,225,226,227$, 229 [т].

Bayle, Pierre. Dictionnaire historique et critique. En GG, X, 1806, núm. 462 [E].

Bayle, Pierre. [ONI]. En GG, vIII, 1804, núm. 340 [M].

Beauzée, Nicolas. Encyclopédie méthodique. Grammaire et Littérature. En GG, VII, 1803, núm. 307 [T].

Bernardin de Saint Pierre, Jacques Henri. Études de la nature. En GG, II, 1798, núms. 52, 53 [T].

Bertholon, Pierre de Saint-Lazare. De l'électricité $d u$ corps humain dans l'état de santé et de maladie. En GG, VI, 1802, núm. 257 [M].

Bielfeld, Jakob Friedrich Von. Instituciones politicas. En GG, II, 1798, núms. 70, 72, 76; VII, 1803, núm. 323 [M, Ti].

Blanchard, Jean-Baptiste. Escuela de costumbres o reflexiones morales e históricas, sobre las máximas de la sabiduría. En GG, VIII, 1804, núm. 367; IX, 1805, núm. 385; x, 1806, núm. 444 [Co]. 
Bodin, Jean. Les six livres de la République. En GG, I, 1797, núm. 3 [Co].

Bodin, Jean. Methodus ad facilem historiarum cognitionem. En GG, I, 1797, núm. 3 [Co].

Boileau-Despréaux, Nicolas [ANI]. [ONI : Le lutrin]. En GG, vI, 1802, núm. 253 [Cita].

Boileau-Despréaux, Nicolas. [on: Art poétique]. En GG, VII, 1802, núm. 315 [т].

Boileau-Despréaux, Nicolas. [ONI]. En GG, X, 1806, núm. $440[\mathrm{M}]$.

Boileau-Despréaux, Nicolas. Véase Blanchard, Escuela de costumbres. En GG, IX, 1805, núm. 385 [Ti].

Boissier de Sauvages, François. Nosologia methodica. En GG, III, 1799, núm. 100; v, 1801, núm. 210 [E].

Bomare. Véase Valmont de Bomare.

Bouillon-Lagrange, Edmé-Jean Baptiste [ANI]. [ONI: Manuel d'un cours de chimie]. En GG, VIII, 1804, núm. 344 [T].

Brisson, Mathurin Jacques. Diccionario universal de fisica. En GG, VI, 1802, núm. 278; vIII, 1805, núm. 381; IX, 1805, núm. 403 [M, Co].

Brown, John. Elementos de medicina del Dr. Juan Brown, amplificados por el doctor Joseph Mariano Moziño. En GG, VI, 1802, núm. 279-Suplemento [Co].

Buffon, Georges Louis Leclerc. "Invocation à 1'Auteur de la Nature", en Génie de M. de Buffon. En GG, X, 1807, núms. 472-473 [т].

Buffon, Georges Louis Leclerc. Discours prononcé à l'Académie française par $M$. de Buffon, le jour de sa réception. En GG, VIII, 1804, núms. 369, 370, $371,372[\mathrm{~T}]$.

Buffon, Georges Louis Leclerc. Historia natural, general y particular. En GG, III, 1799, núm. 118; VII, 1803, núm. 310; IX, 1805, núm. 398 [M].

Buffon, Georges Louis Leclerc. [ONI]. En GG, III, 1799, núm. 122; Iv, 1800, núm. 158; VII, 1803, núms. 310, 311; VIII, 1805, núm. 380; IX, 1805, núms. 388, 398 [M].

Burja, Abel. Observations d'un voyageur sur la Russie, la Finlande, la Livonie, la Curlande et la Prusse. En GG, I, 1797, núm. 37 [т].
Cangiamila, Francesco Emmanuele. Embriología sagrada. En GG, III, 1799, núm. 124 [Co].

Carli, Gian Rinaldo [ANI]. Lettres américaines. En GG, II, 1798, núm. 65; VI, 1802, núm. 248; VII, 1803, núm. 296 [T, M].

Chantreau, Pierre-Nicolas. Arte de hablar bien francés, o gramática completa. En GG, IV, 1800, núm. 182 [E].

Chardin, Jean. Voyages de Monsieur le Chevalier Chardin en Perse et autres lieux de L'Orient. En GG, I, 1797, núm. 3 [T].

Charlevoix, François-Xavier de. Journal d'un voyage fait par ordre du Roi dans l'Amérique septentrionale. En GG, vII, 1803, núm. 315 [T].

Chomel, Noël. Supplément au Dictionnaire Économique contenant divers moyens d'augmenter son bien et de conserver sa santé. En GG, III, 1799, núm. 111 [E].

Clavijero, Francisco Javier. Storia antica del Messico. En GG, I, 1797, núm. 27; II, 1798, núms. 5457, 64, 74, 75, 78; vII, 1803, núms. 296, 316 [Co, T].

Colon, François. Ensayos sobre la inoculación de la vacuna o método fácil, y seguro de preservarse para siempre de las viruelas. En GG, VII, 1803, núm. 290 [M].

Colon, François. [ONI]. En GG, VII, 1803, núm. 305 [M].

Condillac, Étienne Bonnot de. [ANI]. [ONI: Cours d'études pour l'instruction du Prince de Parme]. En GG, vI, 1802, núms. 269, 270, 271 [т].

Condillac, Étienne Bonnot de. El comercio y el gobierno mirados con relación recíproca, en $\mathrm{M}$. J. Suárez, Memorias instructivas y curiosas sobre agricultura, comercio, industria, economía, chymica, botánica é historia natural. En GG, VIII, 1804, núms. 345, 354 [Co].

Condillac, Étienne Bonnot de. La lógica o los elementos del arte de pensar. En GG, VII, 1803, núm. 290; vIII, 1804, núm. 340 [M].

Condillac, Étienne Bonnot de. [ONI]. En GG, v, 1801, núms. 219, 253; vI, 1802, núms. 253, 280 [M].

Condillac, Étienne Bonnot de. [оNI: Essai sur l'origine des connaissances humaines]. En GG, VI, 1802, núm. 252 [T]. 
Condorcet, Nicolas de. Compendio de la obra inglesa intitulada Riqueza de las Naciones hecho por el Marqués de Condorcet. En GG, VI, 1802, núms. 247, 250, 253 [Ti].

Cook, James. Voyage dans l'hémisphère austral, et autour du monde. En GG, II, 1797, núm. 69 [T].

Cornaro, Giuseppe Antonio. La sobriedad y sus ventajas. En GG, vIII, 1804, núm. 367 [Co].

Cournand, Antoine de. Tableau des révolutions de la littérature ancienne et moderne, 1786. En GG, $\mathrm{x}$, 1806, núm. 457 [Co].

Cullen, William. Elementos de medicina práctica. En GG, III, 1799, núm. 100 [Ti].

Cullen, William. [ONI]. En GG, II, 1798, núm. 50 [M].

D'Alembert, Jean Le Rond. Encyclopédie méthodique. Grammaire et Littérature. En GG, VII, 1803, núm. 307 [т].

D'Alembert, Jean Le Rond. [ONI: Encyclopédie méthodique. Grammaire et littérature]. En GG, VI, 1802, núm. 267 [т].

D'Alembert, Jean Le Rond. Réflexions sur l'inoculation. En GG, I, 1797, núm. 26 [т].

Davenant, William. Del uso de la aritmética política en el comercio y rentas. En GG, I, 1797, núm. 19; II, 1798, núm. 92 [Ti].

Degerando, Joseph-Marie. Histoire comparée des systèmes de philosophie. En GG, VIII, 1804, núm. 372 [Co].

Delametherie, Jean Claude. Extracto de un viaje hecho a los trópicos por Mrs. Humboldt y Bompland desde el año 1799 hasta el de 1804. En GG, IX, 1805, núms. 400, 402, 403, 405, 409 [Ti].

Delametherie, Jean Claude. [ONI]. En GG, II, 1798, núm. 91; III, 1799: 14; vI, 253; x, 436, 457 [M, Co].

Delandine, Antoine-François [ANI]. Le Conservateur ou Bibliothèque choisie de Littérature, de Morale et d'Histoire. En GG, IX, 1805, núm. 418; x, 1806, núms. 441, 461 [T].

Duhalde, Jean-Baptiste. Description géographique, historique, chronologique, politique et physique de l'empire de la Chine et de la Tartarie chinoise. En GG, VI, 1802, núm. 267 [M].
Duhamel de Monceau, Henri Louis. Physica de los árboles. En GG, III, 1799, núm. 118 [M].

Dumarsais, César Chesneau. Encyclopédie méthodique. Grammaire et Littérature. En GG, VI, 1802, núm. 241; VII, 1803, núms. 306, 307 [T].

Echard, Lawrence. Diccionario geográfico universal. En GG, I, 1797, núm. 16 [Co].

Enciclopedia metódica. Geografía moderna. En GG, I, 1797, núms. 39, 44; vIII, 1805, núm. 381, IX, 1805, núm. 432 [Ti, Co].

Encyclopédie méthodique. Agriculture. En GG, II, 1798, núm. 57 (Suplemento) [E].

Encyclopédie méthodique. Géographie moderne. En GG, I, 1797, núms. 24, 25, 39, 44; IX, 1805, núm. 432 [Co, T].

Expilly, Jean Joseph. Tableau de la population de la France. En GG, I, 1797, núm. 10 [T].

Facciolati, Jacopo. Véase Gretser, Jacob.

Faiguet de Villeneuve, Joachim [ANI]. [ONI : "Etudes", Encyclopédie méthodique. Grammaire et littérature]. En GG, vI, 1802, núms. 257, 259-261 [E].

Feller, François-Xavier de Feller. Nouveau dictionnaire historique ou Histoire abrégée de tous les Hommes qui se sont fait un nom par des Talens, des Vertus, des Forfaits, des Erreurs \&c. En GG, IV, 1800, núm. 179 [E].

Fénelon, François de Salignac de la Mothe. [ANI]. Las aventuras de Telemaco. En GG, VIII, 1804, núm. 340 [M].

Fénelon, François de Salignac de la Mothe. [ONI]. En GG, II, 1799, núm. 96; III, 1799, núm. 120; VIII, 1805, núm. 381 [M].

Fénelon, François de Salignac de la Mothe. [ONI: Les aventures de Télémaque]. En GG, II, 1798, núm. $76\left[\mathrm{~T}^{*}\right]$.

Fielding, Henry [ANI]. Tom Jones, o el expósito. En GG, VI, 1802, núm. 259 [M].

Fielding, Henry. [ONI]. En GG, vIII, 1804, núm. 337; 1805, núm. 381 [M].

Filangieri, Gaetano [ANI]. [ONI: "Prólogo del traductor", Ciencia de la legislación escrita en italiano por el caballero Cayetano Filangieri. Traducida al castellano por don Jaime Rubio]. En GG, II, 1798, núms. 66, 69, 70 [P1]. 
Fleury, Claude. Catecismo historico que contiene en compendio la historia sagrada y la doctrina cristiana. En GG, VIII, 1804, núm. 351 [M].

Fontaine, Jean Claude. Cours encyclopédique et élémentaire de mathématiques et de physique. En GG, VII, 1803, núm. 290 [M].

Fontenelle, Bernard Le Bouyer de. Digressions sur les Anciens et les Modernes. En GG, X, 1806, núm. 457 [T].

Fontenelle, Bernard Le Bouyer de. Éloges des Académiciens de l'Académie des Sciences. En GG, x, 1806, núm. 457 [M, T].

Fontenelle, Bernard Le Bouyer de. [ONI]. En GG, I, 1797, núm. 3 [M].

Franklin, Benjamin. [ONI]. II, 1798, núm. 56; IV, 1800, núm. 174; X, 1806, 457 [M].

Franklin, Benjamin. Poor Richard's Almanack. En GG, IX, 1805, núm. 414 [Co].

Franklin, Benjamin. Remarks Concerning the Savages of North-America. En GG, v, 1801, núm. 238 [T].

Gage, Thomas. Nouvelle relation contenant les voyages de Thomas Gage en Nouvelle Espagne, en Antoine François Prévost, Historia general de los viajes. En GG, I, 1797, núms. 14, 31; II, 1798, núms. 69, 73; vII, 1803, 323 [TI, Co].

Ganganelli, Giovanni Vincenzo Antonio. Cartas importantes del papa Clemente XIV (Ganganeli). En GG, VII, 1803, núms. 293, 328; VIII, 1804, núm. 341 [Ti].

Genlis, Félicité de [ANI]. Las veladas de la quinta. En GG, VII, 1803, núm. 297; X, 1806, núm. 444 [M].

Genlis, Félicité de. Los anales de la virtud. En GG, X, 1806, núm. 444 [M].

Gérard, Philippe Louis [ANI]. Triunfos de la verdadera religión contra los extravios de la razón en el conde de Valmont. Primera parte traducida del francés por el R.P.Fr. Clemente Millana. En GG, IV, 1800, núm. 150 [Co].

Gessner, Salomon. [ONI] En GG, T. VIII, 1805, núm. 381 [M].

Gessner, Salomon. [ONI: "Les deux amis de Bourbonne", en Contes moraux et Nouvelles Idylles de D[iderot] et Salomon Gessner]. T. X, 1806, núm. 452 [Co].

Gomez, Marie Angélique de [ANI]. Jornadas divertidas, politicas sentencias y hechos memorables de reyes y héroes de la antigüedad. En GG, X, 1806: 452 [Co].

Gretser, Jacob. Institutiones de octo partibus orationis, syntaxi et prosodia Graecorum. En GG, IV, 1801, núm. 192 [Co].

Haldat, Charles Nicolas Alexandre Haldat du Lys. Recherches chimiques sur l'encre, son altérabilité et les moyens d'y remédier. En GG, IX, 1806, núm. 425 [E, Ti].

Haller, Albrecht. Elementa physiologiae corporis humani. En GG, IV, 1800, núm. 171 [Ti].

Hanger, George. The life, adventures, and opinions of Col. George Hanger. En GG, vI, 1802, núm. 243 [T].

Helvétius, Claude Adrien [ANI]. [ONI: De l'Esprit]. En GG, I, 1797, núms. 4, 18; vI, 1802, núm. 267 [T].

Helvétius, Claude Adrien. [ONI]. X, 1807, núm. 470 [Co].

Herder, Johan Gottfried. Outlines of a philosophy of the history of man. En GG, VI, 1802, núms. 241, 246, 247, 249 [T].

Hobbes, Thomas. De Cive. En GG, I, 1797, núm. 39 [Co].

Jefferson, Thomas. Notes on the State of Virginia. En GG, v, 1801, núm. 231 [T].

Jefferson, Thomas. [ONI]. En GG, IX, 1805, núm. 404 [T].

Johnson, Samuel. [ONI]. En GG, X, 1806, núm. 452 $\left[\mathrm{T}^{*}\right]$.

La Bruyère, Jean de [ANI]. [ONI: Les caractères ou les mours de ce siècle]. En GG, III, 1799, núm. 106 [T].

La Harpe, Jean-François. Abrégé de l'histoire générale des voyages. En GG, VIII, 1804, núm. 372 [Co, $\mathrm{T}]$.

La Rochefoucauld-Liancourt, François de. Noticia del estado de las cárceles de Filadelfia. En GG, IX, 1805, núm. 416 [Co]. 
Lacombe de Prézel, Honoré [ANI]. Dictionnaire des hommes illustres. En GG, X, 1806, núm. 457 [Co].

Lamy, Bernard. Traité historique de l'ancienne Pâque des Juifs. En GG, II, 1798, núm. 89 [Co].

Lesage, Alain-René [ANI]. Mélanges amusants des saillies d'esprit et des traits historiques les plus frappants. En GG, VIII, 1804, núm. 340 [M].

Lesage, Alain-René. Aventuras de Gil Blas de Santillana. En GG, II, 1798, núm. 94; VI, 1802, núm. 274; vII, 1803, núm. 323 [M].

Lesage, Alain-René. El bachiller de Salamanca, o aventuras de D. Querubin de la Ronda. En GG, VII, 1803, núm. 323 [Co].

Lieutaud, Joseph. Synopsis universa praxeos medica: in binas partes divisa. En GG, III, 1799, núm. 99 [T].

Mably, Gabriel Bonnot de. Observations sur le gouvernement et les lois des États-Unis d'Amérique, par Mr. L'Abbé de Mably. En GG, I, 1797, núms. 5, $6[\mathrm{~T}]$.

Mairan, Jean Jacques d'Ortous de. Éloges des académiciens de l'Académie Royale des sciences. En GG, X, 1804, núms. 455-457 [M].

Marmontel, Jean-François. Encyclopédie méthodique. Grammaire et Littérature. En GG, VII, 1803, núm. 307 [т].

Marmontel, Jean-François. Les charmes de l'étude. Épître aux poètes. En GG, II, 1798, núm. 56 [Co].

Marshall, John. The life of George Washington. En GG, VIII, 1804, núm. 372 [M].

Martinelli, Vincenzo. Historia crítica de la vida civil. En GG, VIII, 1804, núm. 364 [Ti].

Martini, Antonio. Instrucción sobre el misterio de la Eucaristía como sacrificio. En GG, v, 1801, NúM. 225 [Co].

Masson de Morvilliers, Nicolas. Encyclopédie méthodique. Géographie moderne. En GG, I, 1797, núm. $25[\mathrm{Co}]$.

Mercier, Louis-Sébastien [ani]. [oni: "Discours sur la lecture"]. En GG, VII, 1803, núm. 327 [т].

Mercier, Louis-Sébastien. Mon bonnet de nuit. En GG, X, 1806, núms. 452, 459, 462; 1807, núms. 469, 470 [т].
Metastasio, Pietro. [oni]. En gg, viII, 1804, NúMs. 341, 365; 1805: 381 [Co, TI].

Moivre, Abraham. La dottrina deglo azzardi applicata ai problemi della probabilita' della vita. En GG, I, 1797, núm. 26 [Т].

Moivre, Abraham. [oni]. En GG, vIII, 1804, núm. $343[\mathrm{M}]$.

Montesquieu, Charles Louis de Secondat, baron de [ANI]. [oni: De l'esprit des lois]. En GG, I, 1797, núm. 5 [T].

Montesquieu, Charles Louis de Secondat, baron de [ANI]. [ONI]. En GG, vi, 1802, núm. 280 [M].

Montesquieu, Charles Louis de Secondat, baron de [ANI]. [ONI: Lettres persanes]. En GG, I, 1797, núm. $5[\mathrm{~T}]$.

Montesquieu, Charles Louis de Secondat, baron de. [ont: De l'esprit des lois]. En GG, I, 1797, núm. 3 [Co].

Morhof [Morhosio], Daniel. Polyhistor, sive de auctorum notitia et rerum commentarii. En GG, I, 1797, núm. 33 [Cita].

Muratori, Luis Antonio. Reflexiones sobre el buen gusto en las ciencias y en las artes. En GG, IV, 1800, núm. 186 [Ti].

Necker, Jacques [ANI]. Eloge de Jean Baptiste Colbert. En GG, vII, 1803, núm. 309 [E].

Ongaro, Antonio [ANI]. [onI: Alceo, Favola pescatoria]. En GG, vII, 1803, núm. 328 [Cita].

Pastoret, Claude Emmanuel. Compendio histórico de la vida del falso profeta Mahoma. En GG, I, 1797, núm. 16 [Ti].

Pauw [Paw], Cornelius de. [ONI]. En GG, I, 1797, núms. 14, 44; II, 1798, núms. 54, 65; vI, 1802: $296[\mathrm{M}]$.

Pauw [Paw], Cornelius de. Recherches philosophiques sur les Américains. En GG, I, 1797, núms. 13, 14; 1798: 54, 66 [Co].

Perizonius, Jakob Voorbroek. Edición de Francisco Sánchez de Las Brozas, Minerva, seu de causis linguae latinae commentarius. En GG, IV, 1801, núm. 191 [Co].

Petrarca, Francesco. Il canzionere. En GG, II, 1798, núm. 68; x, 1806, núm. 452 [Cita, M]. 
Pluche, Noël Antoine. [ONI]. En GG III, 1799, núm. 118 [M].

Pluche, Noël Antoine. [ons: Harmonie des Psaumes et de l'Évangile]. En GG, II, 1798: 77 [т].

Pluche, Noël Antoine. Espectáculo de la naturaleza. En GG, II, 1798, núm. 70; III, 1799, núm. 118; VIII, 1805, núms. 381, 383 [Co, M].

Préfontaine [Prejon Taine], Jean Antoine Brûletout de. Maison rustique, à l'usage des Habitants de la France équinoxiale, connue sous le nom de Cayenne. En GG, II, 1798, núm. 54 [T].

Prévost, Antoine François. Historia general de los viajes. En GG, I, 1797, núms. 14, 17; II, 1798, núms. 58, 69, 73 [Ti].

Raynal, Guillaume-Thomas [ANI]. [ONI: Histoire philosophique et politique des établissements et $d u$ commerce des Européens dans les deux Indes]. En GG, IV, 1800, núm. 146; VII, 1803, núm. 331 [T].

Réaumur, René-Antoine Ferchault de. Dissertation sur l'Art de conserver les grains. En GG, III, 1799, núm. $111\left[\mathrm{~T}^{*}\right]$.

Réaumur, René-Antoine Ferchault de. [ONI]. En GG, 10, 1806, núm. 457 [M].

Réaumur, René-Antoine Ferchault de. [ons: Mémoires sur les abeilles]. En GG, II, 1798, núm. 70 [M].

Restaut, Pierre. Principes généraux et raisonnés de la Grammaire française. En GG, IV, 1801, núm. 191 [M].

Ribeiro Sánchez, Antonio [ANI]. Tratado de la conservación de la salud de los pueblos. En GG, II, 1798, núm. 50 [M].

Richardson, Samuel [ANI]. Clara Harlowe. En GG, VI, 1802, núm. 259 [M].

Roberti, Giambattista. [ANI]. [ONI: Dell'amore verso la patria. Trattato]. En GG, II, 1798, núm. 55 [T].

Roberti, Giambattista. Opuscoli quattro sopra il Lusso. En GG, I, 1797, núm. 16 [т].

Rouland, Urbain François. Véase Sigaud de la Fond.

Rousseau, Jean-Jacques [ANI]. [ONI: L'Émile ou de l'éducation]. En GG, I, 1797: 44 [T].

Rousseau, Jean-Jacques. Du contrat social. En GG, II, 1798, núm. 55 [M].
Rousseau, Jean-Jacques. Julie ou la nouvelle Héloïse. En GG, II, 1798, núm. $58^{47}$ [T].

Rousseau, Jean-Jacques. [ONI]. En GG, IX, 1805, núm. 388; x, 1806, núm. 440 [M].

Rozier, François. Curso completo o diccionario universal de agricultura. En GG, VI, 1802, núm. 278; VIII, 1805 núm. 381; IX, 1805, núm. 403; x, 1806, núms. 450, 451 [Co, M].

Rozier, François. Observations sur la physique, sur l'histoire naturelle et sur les arts. En GG, I, 1797, núm. 45; II, 1798, núm. 69; vI, 1802, núm. 288 [E, M].

Rumford, Benjamin Thomson, Count. Ensayos políticos, económicos y filosóficos. En GG, vI, 1802, núm. $263\left[\mathrm{~T}^{*}\right]$.

Rumford, Benjamin Thomson, Count. Recherches sur la nature de la chaleur. En GG, VIII, 1804, núm. 372; x, 1806, núm. 457 [M].

Saint Pierre. Véase Bernardin de Saint Pierre.

Sánchez Valverde, Antonio. América vindicada de la calumnia de haber sido madre del mal venéreo. En GG, VII, 1803, núm. 296 [Co].

Sauvages. Véase Boissier de Sauvages.

Say, Jean-Baptiste. Tratado de economía politica politica o exposición simple del modo como se forman, distribuyen y consumen las riquezas. En GG, IX, 1805, núm. 404 [M].

Seriman, Zaccaria [ANI]. Los viajes de Enrique Wanton a las tierras incógnitas australes, y al pais de las monas. En GG, VII, 1803, núm. 328 [M].

Sigaud de la Fond, Joseph Aignan. Elementos de fisica teórica y experimental. En GG, x, 1806, núm. 457 [M].

Sigaud de la Fond, Joseph Aignan. Essai sur différentes espèces d'air-fixe ou de gas. Nouvelle édition, revue et augmentée par $M$. Rouland. En GG, II, 1798, núms. 56, 57 [T, Co, E].

Sigaud de la Fond, Joseph Aignan. [ONI]. En GG, II, 1798, núm. 50; viII, 1805, núm. 381; x, 1806: $457[\mathrm{M}]$.

47 Otra fuente posible es la entrada "Danse" de la Encyclopédie ou Dictionnaire universel raisonné des connaissances bumaines, 1772. 
Smith, Adam. Compendio de la obra inglesa intitulada Riqueza de las Naciones hecho por el Marqués de Condorcet. En GG, VI, 1802, núms. 247, 250, 253 [Ti].

Smith, Adam. Investigación de la naturaleza y causas de la riqueza de las naciones. En GG, IV, 1800, núms. 173-175, 184 [Ti, Co].

Smith, Adam. [ONI] IV, 1800, núms. 163, 164 [Co].

Sturm, Christoph Christian. Reflexiones sobre la naturaleza o consideraciones de las obras de Dios en el orden natural. En GG, vIII, 1805, núm. 379; x, 1806, núm. 444 [Ti, M].

Swift, Jonathan [ANI]. Viajes del capitán Lemuel Gulliver a diversos países remotos. En GG, VI, 1802, núm. 259 [M].

Thomas, Antoine Léonard [ANI]. [ONI : "De 1'homme de lettres considéré comme citoyen"]. En GG, IV, 1801, núm. 188 [T].

Thomas, Antoine Léonard. Épitre au peuple. En GG, II, 1798, núm. 56 [Co].

Thomas, Antoine Léonard. [ONI]. En GG, vIII, 1805, núm. $381[\mathrm{M}]$.

Valmont de Bomare, Jacques-Christophe. Dictionnaire raisonné d'histoire naturelle. En GG, II, 1798, núm. 57 (Suplemento); III, 1799, núm. 122; VII, 1803, núm. 311 [E].

Vancouver, George. Voyage of discovery to the North Pacific Ocean, and round the world in the years 1791-95. En GG, VII, 1803, núms. 290, 320; vIII, 1804, núm. 358 [Co].
Vandermonde, Alexandre-Théophile. "Economie politique", 1795. En GG, vI, 1802, núm. 242 [T].

Vandermonde, Alexandre-Théophile. [ONI]. En GG, v, 1801, núm. 205 [M].

Vanière, Ignace. Cours de latinité. En GG, IV, 1800, núms. 182, 186; 1801, núm. 192 [M].

Vanière, Ignace. [ONI]. En GG, VIII, 1805, núm. 347 [M].

Vanière, Ignace. Rudimentos de gramática latina. Primera parte del curso de latinidad. En GG, v, 1801, núms. 225, 237; vI, 1802, núm. 243 [M].

Véron Duverger de Forbonnais, François [ANI]. Elementos de comercio. En GG, VII, 1803, núm. 309; VIII, 1804, núm. 344 [Co, Ti].

Voltaire [ANI]. Le fanatisme ou Mahomet le prophète. En GG, II, 1798, núm. 55 [M].

Voltaire [ANI]. [ONI : "Lettre sur le Parlement", en Lettres philosophiques]. En GG, I, 1797, núm. 2 [T*].

Voltaire [ANI]. [ONI : Nouvelles considérations sur l'histoire]. En GG, I, 1797, núm. 10 [T].

Voltaire. [ONI]. En GG, X, 1806, núm. 457; núm. 462; 1807, núm. 470 [E].

Weikard, Melchior Adam. Llave de la práctica medico-Browniana. En GG, vI, 1802, núm. 250 [Ti].

Young, Arthur. [ONI]. En GG, v, 1801, núms. 213$215,217[\mathrm{Co}, \mathrm{E}]$.

Young, Edward. Night thoughts. En GG, v, 1801, núm. 213 [Co].

Young, Edward. Obras selectas de Eduardo Young, expurgadas de todo error. En GG, VI, 1802, núm. 259 [M].

\section{Anexo 2. Menciones de autores modernos (apellidos)}

Addison [Adisson], Joseph. vi, 1802, núm. 274.

Amontons, Guillaume. x, 1806, núm. 457.

Amyot, Jacques. viII, 1805, núm. 380.

Astruc, Jean. viI, 1803, núm. 296.

Baldini [Baldani], Filippo. II, 1798, núm. 76.

Barthélemy, Jean-Jacques. viII, 1805, núm. 381.

Batteux, Charles. x, 1806, núm. 454.

Belon, Pierre. VII, 1803, núm. 310.

Boerhave, Herman. vII, 1803, núm. 296.

Bordeu, Théophile de. x, 1806, núm. 457. 
Bossuet, Jacques-Benigne. III, 1799, núm. 120.

Bourdaloue, Louis. III, 1799, núm. 107.

Buchan, William. vi, 1802, núm. 279-Suplemento.

Camaldoli, Ambrosio. II, 1798, núm. 89.

Caracciolo, Domenico. II, 1798, núm. 96; vIII, 1804, núms. 340, 347.

Coreal [Correal], François. I, 1797, núms. 14, 44.

Corneille, Pierre. vi, 1802, núm. 274; x, 1806, núm. 457.

Cuvier, Georges. vI, 1802, núm. 278.

Daubenton, Louis Jean-Marie. VII, 1803, núm. 311.

Descartes, René. vI, 1802, núms. 253, 297; vII, 1803, núm 314; vIII, 1804, núm. 351; x, 1806, núm. 457.

Dodart, Denis. x, 1806, núm. 457.

Dryden, John. vIII, 1805, núm. 381; x, 1806, núm. 457.

Duméril, André Marie Constant. vi, 1802, núm. 278.

Euler, Leonhard. x, 1806, núm. 457.

Ferrein, Antoine. vII, 1803, núm. 310.

Fléchier, Valentin Esprit. III, 1799, núm. 120.

Fourcroy, Antoine-François. vI, 1802, núm. 278.

Galileo Galilei. vII, 1803, núm. 297; vIII, 1804, 351; x, 1806, núm. 457.

Gassendi, Pierre. X, 1806, núm. 457.

Genovesi, Antonio. II, 1798, núm. 88.

Gibbon, Edward. vIII, 1805, núm. 381.

Graaf, Reinier de. vII, 1803, núm. 310.

Hume, David. I, 1797, núm. 2; vi, 1802, núm. 273.

Ingenhousz, Jan. II, 1798, núm. 57.

Jenner, Edward. IX, 1805, núm. 416.

Jussieu, Antoine Laurent de. vi, 1802, núm. 278.

Kempis, Thomas de. viII, 1804, núm. 351; x, 1806, núm. 444.

Kirwan, Richard. x, 1806, núm. 457.

La Caille, Nicolas Louis. x, 1806, núm. 436.

Lacépède, Bernard-Germain de. vI, 1802, núm. 278.

Lalande, Joseph Jérôme Lefrançois de. III, 1799, núm. 122.

Lavater, Johann Kaspar. x, 1806, núm. 435.

Lavoisier, Antoine. II, 1798, núm. 56.

Leeuwenhoek [Lenwenhoek], Antoni van. vI, 1802, núm. 253.

Leibnitz, Gottfried Wilhelm. vi, 1802, núm. 246, 267; x, 1806, núm. 436, 457.

Linné, Carl. vI, 1802, núm. 253; vIII, 1805, núm. 380; x, 1806, núm. 457.

Locke, John. II, 1798, núm. 96; v, 1801, núm. 219; vi, 1802, núms. 253, 280.

Lodwick, Francis. vi, 1802, núm. 267.

Malebranche [Mallebranche], Nicolas. viII, 1804, núm. 337.

Massillon, Jean-Baptiste. III, 1799, núm. 107; viII, 1804, núm. 340.

Masson de Morvilliers, Nicolas. vi, 1802, núm. 258.

Milton, John. I, 1797, núm. 18; x, 1806, núm. 457.

Molière. vI, 1802, núm. 274.

Newton, Isaac. vII, 1803, núm. 297; vIII, 1804, núm. 351; x, 1806, núm. 436, 457.

Pascal, Blaise. vII, 1803, núm. 297; x, 1806, núm. 457.

Pope, Alexander. vI, 1802, núm. 274; vIII, 1805, núms. 380, 381; x, 1806, núms. 440, 457.

Porta, Giambattista della. x, 1806, núm. 435. 
Poupart, François. x, 1806, núm. 457.

Priestley, Joseph. II, 1798, núm. 56, 57.

Pringle, John. II, 1798, núm. 56; vi, 1802, núm. 288.

Quesnay, François. vi, 1802, núm. 288.

Racine, Jean. x, 1806, núms. 440, 457.

Robertson, William. vII, 1803, núm. 296.

Rogers, Woodes. I, 1797, núm. 14.

Rouland, Urbain François. II, 1798, núm. 56.

Saint Pierre, Charles Irénée Castel de. II, 1798, núm. 55; IV, 1800, núm. 155.

Senebier, Jean. II, 1798, núm. 57.

Sully, Maximilien de Béthune. II, 1798, núm. 55.

Swinburn, Henry. vi, 1802, núm. 258.

Sydenham [Sindenhan], Thomas. x, 1806, núm. 457.

Tasso, Torquato. x, 1806, núm. 457.

Tillotson, John. II, 1798, núm. 55.

Tissot, Samuel Auguste. vI, 1802, núm. 279-Supl.

Torricelli, Evangelista. VII, 1803, núm. 297.

Tournefort, Joseph Pitton de. x, 1806, núm. 457.

Tschirnhaus, Ehrenfried Walther von. x, 1806, núm. 457.

Vanini, Lucilio. VI, 1802, núm. 280.

Varenius (Barenio), Bernhard. x, 1806, núm. 457.

Werner, Abraham Gottlob. viII, 1805, núm. 380.

Wilkins, John. vI, 1802, núm. 267.

Wolf, Christian. v, 1801, núm. 219; vI, 1802, núm. 253.

\section{Anexo 3. Traducciones "integrales"}

\begin{tabular}{|c|c|c|c|c|c|}
\hline Autor TF & Título GG & $\begin{array}{l}\text { Publicación } \\
\text { en GG (Tomo, } \\
\text { año: pág.) }\end{array}$ & Traductor & $\begin{array}{l}\text { Modalidad } \\
\text { de } \\
\text { traducción }\end{array}$ & TF \\
\hline \multicolumn{6}{|c|}{ Bellas letras y filosofía } \\
\hline$[\mathrm{NA}]$ & Elogio del silencio & $x, 1806: 441$ & S. Bergaño & $T$ & $\begin{array}{l}\text { TF: "Eloge du silence", en A. F. } \\
\text { Delandine, Le Conservateur } \\
\text { ou Bibliothèque choisie de } \\
\text { Littérature, de Morale et } \\
\text { d'Histoire, tomo 2, } 1787\end{array}$ \\
\hline Mr. S.* Mar* & $\begin{array}{l}\text { Elogio del hombre } \\
\text { justo }\end{array}$ & $x, 1806: 461$ & S. Bergaño & $T$ & $\begin{array}{l}\text { TF: "L'homme juste", en } \\
\text { Delandine, tomo 1, } 1787\end{array}$ \\
\hline \multirow[t]{2}{*}{$\begin{array}{l}\text { Buffon, } \\
\text { Georges } \\
\text { Louis Leclerc, } \\
\text { Conde de }\end{array}$} & $\begin{array}{l}\text { Discurso } \\
\text { pronunciado } \\
\text { por el conde } \\
\text { de Buffon, } \\
\text { cuando electo } \\
\text { por individuo de } \\
\text { la Academia } \\
\text { Francesa... } 1753\end{array}$ & $\begin{array}{l}\text { VIII, 1804: } \\
370-372 .\end{array}$ & $\begin{array}{l}\text { A. Servidori } \\
\text { S. Bergaño } \\
\text { (probable) }\end{array}$ & RT & $\begin{array}{l}\text { Ed. esp.: "Discurso pronunciado } \\
\text { al tiempo de su recepción en la } \\
\text { Academia francesa", en Vida } \\
\text { del Conde Buffon, 1797. Trad. } \\
\text { José Miguel Alea. } \\
\text { TF: "Discours prononcé à } \\
\text { l'Académie française", } 1777\end{array}$ \\
\hline & $\begin{array}{l}\text { Invocación } \\
\text { al Autor de la } \\
\text { Naturaleza }\end{array}$ & $\begin{array}{l}x, 1807: 472 \\
473\end{array}$ & S. Bergaño & $T$ & $\begin{array}{l}\text { TF: "Invocation à l'auteur de la } \\
\text { Nature", en Génie de M. De } \\
\text { Buffon, } 1778\end{array}$ \\
\hline
\end{tabular}




\section{Anexo 3. Traducciones “integrales” (Continuación)}

\begin{tabular}{|c|c|c|c|c|c|}
\hline Autor TF & Título GG & $\begin{array}{l}\text { Publicación } \\
\text { en GG (Tomo, } \\
\text { año: pág.) }\end{array}$ & Traductor & $\begin{array}{l}\text { Modalidad } \\
\text { de } \\
\text { traducción }\end{array}$ & TF \\
\hline \multicolumn{6}{|c|}{ Bellas letras y filosofía } \\
\hline Favorinus & $\begin{array}{l}\text { Discurso de } \\
\text { Faborino, sobre la } \\
\text { obligación en que } \\
\text { están las madres } \\
\text { de criar por sí } \\
\text { mismas a sus hijos }\end{array}$ & Ix, 1805: 391 & $\begin{array}{l}\text { A. Ramírez } \\
\text { (probable) }\end{array}$ & RT & $\begin{array}{l}\text { Ed. esp. citada: Trad. de } \\
\text { Gregorio Hernández de Velasco } \\
\text { TF citado: Abbé de V..., Les nuits } \\
\text { attiques d'Aulugelle, } 1776 \\
\text { TF original: Aulus Gellius, } \\
\text { "Dissertatio Favorini philosophı, } \\
\text { qua suasit nobili feminae, uti } \\
\text { liberos, quos peperisset, non } \\
\text { nutricum adhibitarum, sed sibi } \\
\text { suo lacte aleret", en Noctes } \\
\text { Atticae, Libro Xlı, ca. } 177\end{array}$ \\
\hline $\begin{array}{l}\text { Herder, } \\
\text { Johan } \\
\text { Gottfried }\end{array}$ & $\begin{array}{l}\text { Climas de } \\
\text { América. De las } \\
\text { lenguas. } \\
\text { De las invenciones } \\
\text { y descubrimientos }\end{array}$ & $\begin{array}{l}\text { VI, 1802: } 241 \\
246,247,249\end{array}$ & $\begin{array}{l}\text { A. Ramírez } \\
\text { (probable) }\end{array}$ & T & $\begin{array}{l}\text { TF: Outlines of a Philosophy of the } \\
\text { History of Man, } 1800\end{array}$ \\
\hline \multirow{3}{*}{$\begin{array}{l}\text { Mercier, } \\
\text { Louis- } \\
\text { Sébastien }\end{array}$} & La ciencia & x, 1806: 459 & S. Bergaño & $T$ & $\begin{array}{l}\text { TF: Mon bonnet de nuit, tomo ll, } \\
1784\end{array}$ \\
\hline & Escritura & $\begin{array}{l}x, 1807: 469 \\
470\end{array}$ & S. Bergaño & $T$ & $\begin{array}{l}\text { TF: Mon bonnet de nuit, tomo I, } \\
1784\end{array}$ \\
\hline & La amistad & $x, 1807: 470$ & S. Bergaño & $T$ & $\begin{array}{l}\text { TF: Mon bonnet de nuit, tomo I, } \\
1784\end{array}$ \\
\hline Ovidio & Epístola & $x, 1806,462$ & S. Bergaño & $T$ & Tristia, Libro V \\
\hline \multicolumn{6}{|c|}{ Historia, usos y costumbres } \\
\hline$[\mathrm{NI}]$ & $\begin{array}{l}\text { Discurso de un } \\
\text { diputado de } \\
\text { cierta nación } \\
\text { salvaje de } \\
\text { la América } \\
\text { Setentrional al } \\
\text { Congreso de los } \\
\text { trece Estados } \\
\text { Unidos }\end{array}$ & Ix, 1805: 418 & $\begin{array}{l}\text { S. Bergaño } \\
\text { (D. S. B. y } \\
\text { V.) }\end{array}$ & T & $\begin{array}{l}\text { tF: "Discours d'un Député d'une } \\
\text { Nation Sauvage de l'Amérique } \\
\text { septentrionale au Congrès des } \\
\text { treize Etats Unis", en Delandine, } \\
\text { tomo } 2,1787\end{array}$ \\
\hline $\begin{array}{l}\text { Clavijero, } \\
\text { Francisco } \\
\text { Javier }\end{array}$ & $\begin{array}{l}\text { Sobre la religión } \\
\text { de los antiguos } \\
\text { mexicanos; Sobre } \\
\text { la población del } \\
\text { antiguo México; } \\
\text { Sobre las leyes de } \\
\text { los mexicanos; } \\
\text { Lenguas de } \\
\text { América }\end{array}$ & $\begin{array}{l}\|, 1798: 54 \\
55,56,57,64, \\
74,75,78 . \text { v\|, } \\
1803: 316\end{array}$ & $\mathrm{NI}$ & $T$ & $\begin{array}{l}\text { TF: Storia antica del Messico, } \\
1781 \text { (Dissertazioni VI, VII, VIII) }\end{array}$ \\
\hline
\end{tabular}




\section{Anexo 3. Traducciones "integrales” (Continuación)}

\begin{tabular}{|c|c|c|c|c|c|}
\hline Autor TF & Título GG & $\begin{array}{l}\text { Publicación } \\
\text { en GG (Tomo, } \\
\text { año: pág.) }\end{array}$ & Traductor & $\begin{array}{l}\text { Modalidad } \\
\text { de } \\
\text { traducción }\end{array}$ & TF \\
\hline \multicolumn{6}{|c|}{ Bellas letras y filosofía } \\
\hline $\begin{array}{l}\text { Franklin, } \\
\text { Benjamin }\end{array}$ & $\begin{array}{l}\text { Hospitalidad } \\
\text { de los indios } \\
\text { mohawks }\end{array}$ & v, 1801: 238 & $\begin{array}{l}\text { A. Ramírez } \\
\text { (probable) }\end{array}$ & $T$ & $\begin{array}{l}\text { TF: Remarks Concerning the } \\
\text { Savages of North-America, } 1784\end{array}$ \\
\hline $\begin{array}{l}\text { Hanger, } \\
\text { George }\end{array}$ & $\begin{array}{l}\text { Proyectos } \\
\text { donosos de un } \\
\text { devoto inglés } \\
\text { para aumentar } \\
\text { la renta pública, } \\
\text { mejorando las } \\
\text { costumbres }\end{array}$ & VI, 1802: 243 & $\begin{array}{l}\text { A. Ramírez } \\
\text { (probable) }\end{array}$ & $T$ & $\begin{array}{l}\text { TF: The Life, Adventures, and } \\
\text { Opinions of Col. George } \\
\text { Hanger, Written by Himself, } 1801\end{array}$ \\
\hline \multicolumn{6}{|l|}{ Medicina } \\
\hline $\begin{array}{l}\text { Aikin, Charles } \\
\text { Rochemont }\end{array}$ & $\begin{array}{l}\text { Tratado sobre la } \\
\text { vacuna }\end{array}$ & $\begin{array}{l}\mathrm{VI}, 1802: 277 \\
279,281\end{array}$ & $\begin{array}{l}\text { A. Ramírez } \\
\text { (probable) }\end{array}$ & E-T & $\begin{array}{l}\text { TF: Jennerian discovery, or a } \\
\text { concise view of all the most } \\
\text { important facts which have } \\
\text { hitherto appeared concerning } \\
\text { the vaccine or cow-pox, } 1801\end{array}$ \\
\hline $\begin{array}{l}\text { Barton, } \\
\text { Benjamin } \\
\text { Smith }\end{array}$ & $\begin{array}{l}\text { Memoria sobre } \\
\text { los güegüechos, } \\
\text { o paperas, } \\
\text { sus causas, } \\
\text { prevención y } \\
\text { curación de esta } \\
\text { enfermedad }\end{array}$ & $\begin{array}{l}v, 1801: 210 \\
211,213,216 \\
218,221,224 \\
225,226,227 \\
229\end{array}$ & $\begin{array}{l}\text { A. Ramírez } \\
\text { (probable) }\end{array}$ & E-T & $\begin{array}{l}\text { tF: A memoir concerning the } \\
\text { disease of goitre as it prevails in } \\
\text { different parts of North-America, } \\
1800\end{array}$ \\
\hline
\end{tabular}

